University of Rhode Island

DigitalCommons@URI

Open Access Dissertations

2015

\title{
Multivariate Measurement of Multiple Health Behavior Change and Its Relation to Baseline Severity
}

Kelsey Elise Ufholz

University of Rhode Island, kelsey_ufholz@my.uri.edu

Follow this and additional works at: https://digitalcommons.uri.edu/oa_diss

\section{Recommended Citation}

Ufholz, Kelsey Elise, "Multivariate Measurement of Multiple Health Behavior Change and Its Relation to Baseline Severity" (2015). Open Access Dissertations. Paper 402.

https://digitalcommons.uri.edu/oa_diss/402

This Dissertation is brought to you for free and open access by DigitalCommons@URI. It has been accepted for inclusion in Open Access Dissertations by an authorized administrator of DigitalCommons@URI. For more information, please contact digitalcommons-group@uri.edu. 
MULTIVARIATE MEASUREMENT OF MULTIPLE HEALTH BEHAVIOR CHANGE AND ITS RELATION TO BASELINE SEVERITY

BY

KELSEY ELISE UFHOLZ

A DISSERTATION SUBMITTED IN PARTIAL FULFILLMENT OF THE

REQUIREMENTS FOR THE DEGREE OF

DOCTOR OF PHILOSOPHY

IN

PSYCHOLOGY

UNIVERSITY OF RHODE ISLAND 


\title{
DOCTOR OF PHILOSOPHY DISSERTATION
}

\author{
$\mathrm{OF}$
}

\section{KELSEY ELISE UFHOLZ}

\section{APPROVED:}

Dissertation Committee:

Major Professor: Joseph S. Rossi

Colleen Redding

Cynthia Willey-Temkin

Nasser H. Zawia

DEAN OF THE GRADUATE SCHOOL

UNIVERSITY OF RHODE ISLAND 


\begin{abstract}
Unhealthy lifestyle behaviors have been shown to significantly increase the risk of chronic illness. Interventions changing multiple health behaviors simultaneously show promise in reducing mortality, even more than interventions focusing on individual health behaviors. Multiple health behavior change is a new field with many fundamental questions unanswered, among them how to simultaneously measure progress in multiple health-related behaviors. Previous studies have examined several potential multivariate measurement methods but none have shown consistently superior results. Furthermore various methods may best be suited to specific behaviors, study goals, or intervention contexts. This study proposed to compare several of the most commonly used measurement methods within the context of a study examining how overall baseline severity is related to a person's ability to make positive health-related changes. This study consisted of a secondary data analysis from three randomized controlled trials for primary cancer prevention in the general population. Participants were proactively recruited based upon at risk behavior for cigarette smoking, sun exposure, or unhealthy dietary fat intake. Behaviors were examined in pairs. Participants were randomly assigned to either a treatment group which received an intervention based upon the transtheoretical model for all at risk behaviors or a control condition receiving only health behavior assessment. Health behavior change methods studied included summative indices, $\mathrm{z}$-scores, standardized residuals, and progress through the stages of change. Several methods were examined to determine which method best describes the relationship between baseline severity and post-intervention outcomes. Results indicate that participants with healthier
\end{abstract}


baseline behavior profiles demonstrated better post-intervention outcomes.

Demographic characteristics showed comparatively smaller effects. Methods which allowed for greater detail, such as z-scores and movement through the stages of change showed greater sensitivity as evidenced by larger effect sizes. Summative indices and standardized residuals showed statistically significant results with smaller overall effects. Interventions may wish to consider tailoring based upon participant's baseline behaviors. Future studies may wish to expand the generalizability of these methods with more diverse populations, different combinations of behaviors, and/or a different set of predictor variables. 


\section{ACKNOWLEDGEMENTS}

I would like to thank my major professor, Dr. Joseph Rossi for his guidance and insight both while completing this dissertation and during my time in graduate school. Thanks are also due to my committee members, Dr. Colleen Redding, Dr. Cynthia Willey-Temkin, Dr. Andrea Paiva, and Dr. Susan Rossi. I would also like to thank Dr. James Prochaska for access to the datasets used in this dissertation.

I would especially like to thank my family for their immeasurable support and patience, without which this would not have been possible. 


\section{TABLE OF CONTENTS}

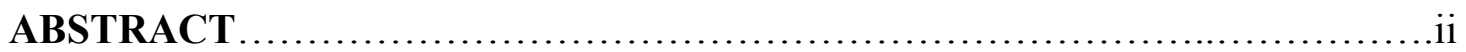

ACKNOWLEDGEMENTS ................................................. iv

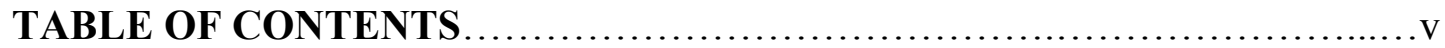

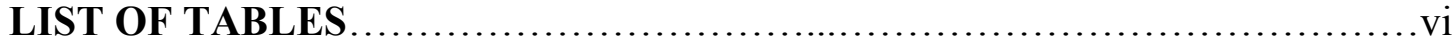

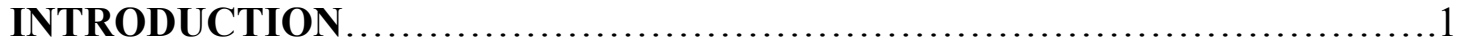

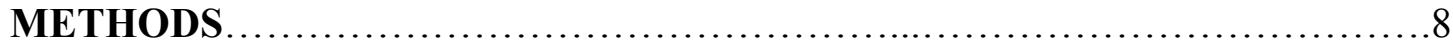

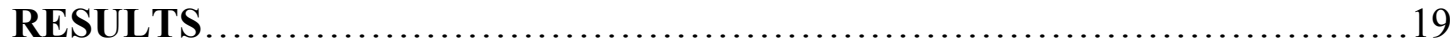

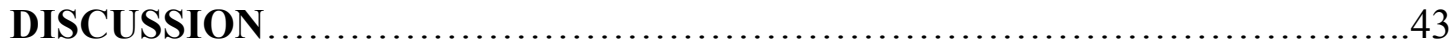

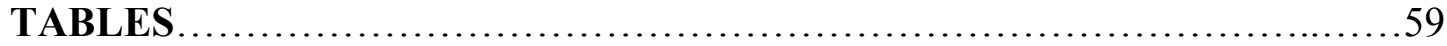

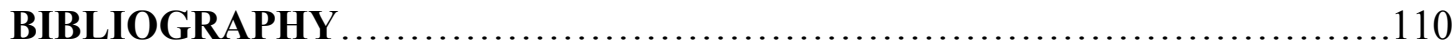




\section{LIST OF TABLES}

TABLE

PAGE

Table 1. Analytic Strategy for Multiple Health Behavior Change

Table 2. Descriptive Statistics for Total Sample

Table 3. Stage of Change at Baseline....

Table 4. Stage of Change at 24 month time-point.

Table 5. Descriptive Statistics of the dependent variables

Table 6. Correlations between baseline and post-intervention scores of 3 behaviors..65

Table 7. Distribution of Participants Reaching Desired Criteria Post-Intervention, single behaviors. .66

Table 8. Distribution of Participants meeting criteria post-intervention, behavioral

pairs.

Table 9. Dummy Coding for Categorical Variables in Multiple Regression. .68

Table 10. Summative index, Multiple regression, sun and smoking, without standardized severity. 69

Table 11. Summative index, Poisson regression, smoking and sun protection, without standardized severity.

Table 12. Summative index, Multiple regression, smoking and diet, without standardized severity. .71 
Table 13. Summative index, Poisson regression, smoking and diet without

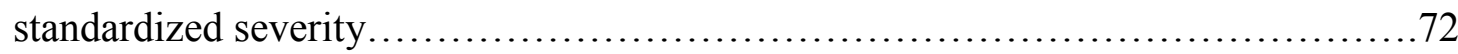

Table 14. Summative Index, Multiple regression, sun and diet, without standardized severity.

Table 15. Summative index, Poisson regression, sun and diet, without standardized severity. .74

Table 16. Summative index, Multiple regression, sun and smoking, with standardized severity .75

Table 17. Summative index, Poisson regression smoking and sun, with standardized severity. .76

Table 18. Summative index, Multiple regression, smoking and diet, with standardized severity .77

Table 19. Summative index, Poisson regression smoking and diet, with standardized severity .78

Table 20. Summative index, Multiple regression, sun and diet, with standardized severity.....

Table 21. Summative index, Poisson regression sun and diet, with standardized severity

Table 22. Z-scores, smoking and sun protection, with standardized severity.

Table 23. Z-scores, diet and smoking, with standardized severity .82 
Table 24. Z scores diet and sun, with standardized severity

Table 25. Standardized Residuals .84

Table 26. Standardized Residuals Smoking and Sun, with standardized severity......85

Table 27. Standardize Residuals, smoking and diet, with standardized severity.......86

Table 28. Standardized Residuals sun and diet, with standardized severity

Table 29. Discriminant Function Analysis, smoking and sun summative indices,

overall effect. .88

Table 30. Discriminant Function Analysis, smoking and sun summative indices,

discriminant loadings

Table 31. Discriminant Function Analysis, smoking and diet summative indices,

overall effect.

Table 32. Discriminant Function Analysis, smoking and diet summative indices, discriminant loadings

Table 33. Discriminant Function Analysis, sun and diet summative indices, overall

effect.

Table 34. Discriminant Function Analysis diet and sun summative indices, discriminant loadings. .93 
Table 35. Discriminant Function Analysis, smoking and sun, stage of change, overall effect.

Table 36. Discriminant Function Analysis, smoking and sun, stage of change, discriminant loadings.

Table 37. Discriminant Function Analysis, smoking and diet, stage of change, overall effect. .96

Table 38, Discriminant Function Analysis, smoking and diet, stage of change, discriminant loadings

Table 39. Discriminant Function Analysis, sun and diet, stage of change, overall effect .98

Table 40. Discriminant Function Analysis, sun and diet, stage of change, discriminant loadings.

Table 41. Descriptives of Composite Post-Intervention Stage of Change.

Table 42. Post-intervention Composite Stage of Change.

Table 43. Post-Intervention, sun and smoking, without standardized severity .103

Table 44. Post-Intervention, diet and smoking, without standardized severity .104

Table 45. Post-Intervention Stage of Change, sun and diet, without standardized severity .105 
Table 46. Post-Intervention Stage of Change, smoking and sun, with standardized

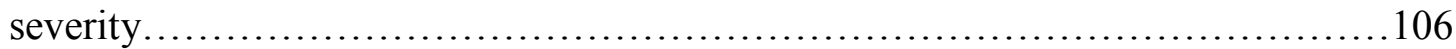

Table 47. Post-Intervention Stage of Change, smoking and diet, with standardized

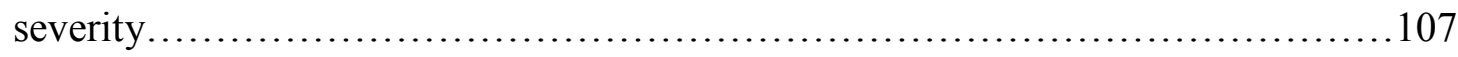

Table 48. Post-Intervention Stage of Change, sun and diet, with standardized

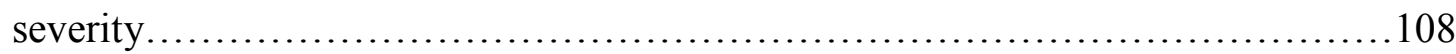

Table 49. Summary of effect sizes....................................... 109 


\section{INTRODUCTION}

The current disease burden in the developed world focuses on chronic illnesses such as cancer, cardiovascular disease, and diabetes. Current estimates indicate that $7.2 \%$ of the adult population in the United States has a history of cancer (excluding non-melanoma skin cancer) (Underwood, 2012). This number is expected to increase as the general population ages (Parry et al., 2011). Rates of cardiovascular disease and diabetes are also expected to climb (Mathers \& Loncar, 2006).

It is well-known that certain health behaviors can decrease the risk of these diseases (Blair et al., 1996; National Research Council, 1989; USDHHS, 1991). Despite the established association between these health behaviors and chronic illness, very few adults meet these requirements. A study by the Center for Disease Control and Prevention (2007) found that in 2005 only about $27.2 \%$ of adults ate as much as three or more servings of vegetables per day and only $32.6 \%$ ate fruit two or more times per day. In 2011, 19\% of American adults smoked (CDC, 2012). In 2008, only $58 \%$ of American adults reported using sun protection methods, such as seeking shade or wearing sunscreen (CDC, 2013; NCI, 2008). Because of the strong connection between poor diet, smoking, sun exposure, and common chronic illnesses, encouraging people to engage in these health-promoting behaviors has become a major public health imperative.

\section{Multiple Health Behavior Change Theory}

There are a plethora of theories applicable to health behavior change. A review of recent research using health behavior change theory found that the most commonly 
employed theories were the Transtheoretical Model (TTM), Social Cognitive Theory (SCN), and Health Belief Model (HBM) (Painter et al., 2008). Until recently, most health behavior research has focused upon single behaviors. There is now evidence that the effects of healthy behaviors are synergistic, such that multiple healthy behaviors lead to greater reductions of illness and subsequently mortality (Ford et al., 2012; Loef \& Walach, 2012) and that health behaviors are linked such that persons who engage in one health-promoting behavior are more likely to engage in several behaviors (Berrigan et al., 2003). Furthermore, recent research has shown that individuals who are able to make positive changes in one health-related behavior are more likely to make similar progress on a separate behavior (Paiva et al., 2012). For this reason, multiple health behavior change is gaining increased prominence as a paradigm with the potential to significantly reduce disease-promoting behaviors at a population level (Prochaska, Spring \& Nigg, 2008).

Because of its novelty, multiple health behavior change (MHBC) research still has many unanswered questions. Often these questions concern fundamental conceptualizations, such as whether MHBC works via a common set of behavioral change principles that apply equally to all health behaviors, whether general health attitudes give rise to attitudes towards specific health behaviors, which in turn give rise to that behavior, or if change in one "gateway" behavior may lead to subsequent (sequential not simultaneous) change in another behavior (Noar, Chabot \& Zimmerman, 2008). Other unanswered questions include what mechanisms cause multiple behavior change to have a greater impact upon behavior than intervention on a single behavior. Furthermore, it is unknown if there is a maximum number of 
behaviors which can be simultaneously intervened upon (Nigg, Allegrante, \& Ory, 2002). While many of these issues will require empirical studies designed to investigate these questions (e.g., RCTs), existing studies may be able to shed some light on these problems.

\section{Measurement}

To determine how multiple behaviors change together, these behaviors must be measured together. Prochaska and colleagues (2008a) outline a few of the major methodological challenges of measuring multiple behavior change. These include whether to measure change in each behavior individually or to create a composite score encapsulating change in all the behaviors. Other ideas include creating an index of behaviors in which a person is now meeting recommended guidelines and is no longer at risk. Lastly, there is also the option of more holistic measures such as reductions in mortality, increased quality of life, or via some other biometric. Often, even in research when multiple behaviors are examined, they are considered simply as several single behaviors, rather than as part of an overall behavior profile.

Each behavior has its own metric, such as number of cigarettes per day for smoking and total fat intake for diet. Furthermore, individuals will be at different levels of severity for each behavior. For example, a smoker may consume a few cigarettes or a few packs of cigarettes per day; a person may never eat fruit and has not in many years or may fall only a few servings short of recommended criteria. Each individual will have different combinations of severity for different combinations of behavior. This variability of combinations will likely impact which combination of 
behaviors a person attempts to change. For example, they may decide to change the behavior which they perceive as the greatest health risk, the one where they are currently farthest from maintaining healthy habits, or the easy-to-achieve low-hanging fruit. This does not even begin to examine the ways in which changes in one area might have repercussions in another area, either deliberately or as a fortunate sideeffect. Additionally, there may be theoretical differences in behavior types, such as addictive vs. non-addictive behaviors and/or adoption vs. cessation behaviors (Noar \& Zimmerman, 2005), which may further translate into permutations of behavior combinations, all of which must be considered when attempting to assess global severity of healthy behavior.

Some research indicates that baseline severity, or how much a person must change their behavior to meet recommended guidelines, is related to likelihood of successfully adopting healthy habits. Prior research with these data has shown that persons with relatively healthier initial behaviors are more likely to successfully change their habits, both for single behaviors such as cigarette smoking (Velicer et al., 2007; Redding et al., 2011), diet (Greene et al., 2013), sun protection (Yusofov et al., 2014) and for multiple health behaviors (Blissmer et al., 2010). This may be especially relevant in comparison to demographic characteristics, which cannot be altered and tend to have null or inconsistent effects across treatments (Blissmer et al., 2010).

A few methods of measuring MHBC have been considered. For example, recent research by Kobayashi (2012) has considered several methods of measuring MHBC in a population at risk for cigarette smoking, dietary fat intake, and poor sun protection behavior. These include number of behaviors in which a person is now 
meeting recommended guidelines, total progression on stages of change scores, or measures on standardized effect sizes (Kobayashi, 2012; Kobayashi et al., 2014). Other researchers have utilized identical or similar methods including standardized residuals, optimal linear combination, and expanded intervention impact approaches (Carlson et al., 2012; Drake et al., 2013).Other research has examined multiple health behavior change by simultaneous measurement of individual behaviors which have then been analyzed separately (Blissmer et al., 2010). Both areas represent important initial steps in conceptualizing MHBC measurement. However, there is yet to be a study examining multiple combinations of different health behaviors, simultaneously changed and holistically measured. In other words, there is no accepted standard of MHBC measurement.

Establishing such a standard would be an important forward step in advancing MHBC theory. A common method for MHBC would allow future researchers to investigate a variety of unanswered questions such as are some health behavior combinations more impactful, what is the maximum number of behaviors which may be changed at once, or what psychosocial processes facilitate MHBC. Therefore finding the measurement method which best describes MHBC is a necessary next step in health behavior change research.

\section{Multicultural Consideration}

Many demographic factors are also associated with health-related behaviors and merit consideration. For example, Dehghan and collegues (2011) found that fruit and vegetable consumption varied based upon factors such as marital status, 
education, age, and gender. Differences in meeting dietary recommendations have also been found across racial groups, with non-Hispanic blacks often showing the worst outcomes (Kirkpatrick et al., 2011). Research on smoking has found significant racial differences in lifetime incidence of smoking and level of smoking severity (Trinidad et al, 2011). Incidence of sunburn has also been found to significantly differ based upon racial group (Buller et al., 2011).

In regards to MHBC, Blissmer and colleagues (2011) found that for behavioral interventions designed to promote better diet, sun protection, and smoking cessation behaviors, stage progression did not significantly differ based upon ethnicity. This is consistent with previous research which has shown that compared to the impact of variables within behaviors themselves, demographics tend to show small or nonsignificant effect sizes (Velicer et al., 2007). Nonetheless, differences in baseline severity have been found to vary across racial groups, and lack of differences in the previous studys' univariate analyses did not preclude the possibility that differences may exist when examined at the multivariate level. Therefore, ethnicity must be considered as a potentially influential covariate.

\section{Hypotheses}

Prior research has shown that improvement in more than one health-related behavior produces greater overall health improvement compared to changes in a single behavior. However, because MHBC is an emerging field, no recommended method of multivariate measurement has emerged. Therefore efficacy of several MHBC methods was considered and compared, both in terms of amount of variance accounted for and 
practical utility within the context of a research intervention. No a priori predictions about which method would prove most sensitive or useful were made.

A person's ability to make health-related changes is inversely related to initial severity of those behaviors. This study examined how initial severity of overall health behavior was related to a person's ability to make health-related changes, using several alternative multivariate measurement methods. It was predicted that those with healthier initial profiles, as implicated by overall severity indices, will show better post-intervention outcomes. 


\section{METHODS}

\section{Participants}

This study consisted of a secondary analysis of integrated data from several previously collected primary studies. Data were combined from three separate randomized controlled trials. All trials examined three cancer-prevention behaviors: smoking, diet, and sun exposure. The studies utilized similar interventions, including measures, procedures, and assessment time-tables. At-risk participants were proactively recruited from the general population, rather than using clinical samples. Study data were collected between the years 1995 - 2000 and were funded by a grant from the National Cancer Institute. All study participants were at risk for at least one of the behaviors listed above.

Study 1 consisted of the parents of $9^{\text {th }}$ grade students in a northeastern state $(N$ = 1096). Participants from Study 2 were patients from a list provided by primary care practices associated with a large health insurance company $(N=2417)$. Study 3 was done as part of an employee workgroup at a total of 22 worksites $(N=684)$. Total sample size was $\mathrm{N}=4197$. Details of sample recruitment are recorded in previous literature for Study 1 (Prochaska et al., 2004), Study 2 (Prochaska et al., 2005), and Study 3 (Velicer et al., 2004). The demographics and stage of change distribution were found to be comparable across studies (Yin et al., 2013). Participants were included in the study's main analyses if they had complete, accurate data for the dependent variables at all time-points and could be correctly classified into one of the three primary studies.. All participants were required to speak English, be over the age of 
18, provide informed consent, and to be at risk for at least one health behavior. Primary studies were approved by the appropriate Institutional Review Boards.

\section{Intervention}

Study interventions were based upon the Transtheoretical Model (TTM) (Prochaska \& DiClemente, 1984). TTM is one of the most established and frequently used theories of health behavior change (Painter et al., 2008). The underlying principles of the model have been found to apply to many different health behaviors (Hall \& Rossi, 2008; Prochaska, 1994; Prochaska et al., 1994). Furthermore TTMbased interventions on multiple health behaviors have been shown to lead to improvement on more than one behavior compared to controls (Prochaska et al., 2004, 2005).

Participants were randomly assigned to either a treatment or control group. The intervention consisted of a multiple behavior self-help manual based upon TTM strategies and a series of computer-generated individualized feedback reports on all behaviors found to be at risk at baseline. Participants received a five-section report for each behavior, focusing on stage of change, the pros and cons of changing, feedback on up to six processes related to change, suggestions for managing situational temptations, and strategies for taking small steps toward the next stage. Feedback also compared participant progress both to the most successful self-changers within that stage and to data from the participants' prior assessments (Redding et al., 1999; Velicer et al., 2004). Reports were mailed to participants in the intervention group at baseline, 6 months, and 12 months later. Follow-up assessments were made at 12 and 
24 months. The control group was assessed on outcome measures at 12 and 24 months.

Measures

The health-related behaviors included diet, cigarette smoking, and sun protective behaviors. These measures, along with those designed to measure stage of change for each behavior, were used to calculate independent and dependent variables in the analyses. Number of cigarettes smoked per day was used to assess smoking severity, as it is regarded as the single best indicator of smoking severity from Fagerstrom's scale of addiction severity (Fagerstrom, Heatherton, \& Kozlowski, 1990). Dietary risk was assessed by measuring total scores on healthy eating behaviors via the Dietary Behavior Questionnaire (DBQ) (Prochaska et al., 2004, 2005; Rossi et al., 1996). This scale consists of 22 -items assessing food consumption over the previous month. The four subscales correspond to 1) Substitution, or replacing high-fat foods with low-fat foods, 2) Avoidance, or lessening the frequency and quantity of high-fat foods, 3) Modification, or changing cooking techniques to incorporate more low-fat foods, and 4) Fruit and Vegetables, or increasing intake of fruits and vegetables. Internal consistency for adults ranges from $\alpha=.67$ to $\alpha=.84$ (mean $\alpha=.75$ ). The DBQ has been found to be sensitive to dietary change (Greene et al., 1996; Prochaska et al., 2004).

Sun exposure was measured using the Sun Protection Behavior Scale (SPBS), a seven item scale for assessing level of sun protective behaviors during sun exposure, with higher scores reflecting more protective sun behavior (Weinstock et al., 2002). 
This scale consists of two subscales, Sunscreen Use and Sun Avoidance. For adults, previous research has found good reliabilities, ranging from $\alpha=.82$ for the total scale, $\alpha=.86$ for sunscreen use, and $\alpha=.82$ for sun avoidance. The SPBS has been found to be sensitive to the effects of interventions designed to promote sun protective behavior (Weinstock et al., 2002).

Stage of change for smoking cessation was determined via a 6-item algorithm examining baseline intentions and actions with demonstrated predictive validity (DiClemente et al., 1991). All items consisted of yes-no questions. Based upon their answers, smokers were assigned to the 1) precontemplation stage if they did not plan to quit smoking within six months, 2) contemplation stage if they planned to quit smoking within six months, 3) preparation stage if they planned to quit smoking within the next month and had made at least one attempt to stop smoking for 24 hours in the past 12 months, 4) the action stage if they had quit smoking within the previous six months, or 5) maintenance if they had successfully quit smoking for six months or longer.

Stage of change for intention to reduce risky sun behavior was assessed via a series of six questions. Stage determination followed the same format as that used for smoking, with a few exceptions. The quit attempt at the preparation stage was not included and action criteria was determined by consistently limiting time in the sun to 15 minutes or less or always using sunscreen with a minimum SPF of 15 . The overall time-frame was shifted to 12 months rather than six, to account for seasonal differences in sun exposure. This method has been effectively used in prior studies (Weinstock et al., 2000, 2002). 
Stage of change for dietary fat reduction was determined via a series of three questions (Greene et al., 1994). Participants answering "no" to the question, "do you consistently avoid eating high-fat foods" were assigned to precontemplation, contemplation, or preparation, based upon their intentions to change their behavior and the time-frame of this change. Participants answering "yes," were required to meet a behavioral criterion in which less than $30 \%$ of their caloric intake was from dietary fat to be classified as in the action or maintenance stage. Participants not meeting the behavioral criterion were classified as in the precontemplation, contemplation, or preparation stage of change based upon their intentions to alter their eating habits (Greene et al., 1994). This staging algorithm has demonstrated predictive validity (Greene et al., 2012)

Additional measures include those utilized in the intervention to create the individualized progress reports. These consisted of the Processes of Change Inventory (Greene et al., 2013; Prochaska et al., 1988; Yusofov et al., 2014), the Situational Temptation Inventory (Velicer et al., 1990), and the Decisional Balance Inventory (Prochaska et al., 1994). All of these were administered in short form, which have been found to be highly correlated with the long-form versions, and additionally have adequate reliability.

\section{Procedures}

Preliminary Analyses. A variety of potential analytic methods have been proposed. However, as of yet, there is no established method of quantifying multiple behavior change. Therefore, several were compared. Because this research focused 
upon simultaneous change in multiple behaviors and the number of individuals at risk for smoking is relatively low $(N=790)$, only behavioral dyads were considered. The behavioral combinations examined included smoking and diet, smoking and sun protection, and sun protection and diet. Baseline levels of each behavior were operationalized by cigarettes smoked per day, overall healthy diet score, and level of sun protection behaviors.

Preliminary descriptive statistics were run and statistical assumptions including normality, linearity, and homogeneity of variance investigated. To ensure their compatibility, the three studies were compared in terms of gender, marital status, ethnicity, overall health status, and baseline scores on the three behaviors. Attrition rates were examined based upon baseline scores to determine if there were significant differences in whether or not participants completed the intervention. Differences were expected based upon previous studies (Greene et al., 2013). However these were not anticipated to adversely impact results, as the purpose of this study was to establish a new measurement method and not to determine primary outcomes.

Because these same data have been examined in prior studies focused on single behavior change, initial analyses replicated those results as a way to examine validity and reliability (Blissmer et al., 2010; Greene et al., 2013; Redding et al., 2011).

Degree of severity for each behavior was determined by calculating the difference between current baseline behavior and desired behavior for each variable. Desired outcomes were defined as reaching the action or maintenance stage for the given behavior. For smoking, this was defined as complete cessation. To ensure 
consistency across behaviors, standardized scores for cigarettes were reverse scored, such that higher scores reflect healthier outcomes. For dietary behavior, this was defined as average scores on the DBQ of at least 86.20 or higher, corresponding to average total scores for those participants reaching the action or maintenance stages. For sun protection, this was defined as average scores on the SPBS of at least 30.02, the average total score for those participants reaching the action or maintenance stage. This severity score was then standardized by dividing it by the total sample standard deviation of each behavior, to make severity comparable across behaviors. While the mean score was taken from the subset of participants reaching action or maintenance, the pooled standard deviation from the total sample of participants with data for each behavior was used, so that all comparisons were made against the same base. Additionally, this provided stability because only a minority of participants ever reached the desired criteria.

Separate standard deviations were calculated for each behavior at baseline and 24 months. Post-intervention outcomes scores were calculated, in the same manner as pre-intervention severity scores. A total severity index was calculated by summing individual scores and converting them into an effect size. In addition, stage of change for each behavior was determined both pre and post intervention, via the methods previously described. A composite stage of change score was determined by assigning each stage a numeric value (precontemplation $=1$, contemplation $=2$, preparation $=3$, action $=4$, maintenance $=5$ ) and then summing stage of change scores across behaviors. 
Major Analyses. The impact of severity on post-intervention outcomes was analyzed several different ways. To better compare these methods, each analysis utilized the same group of independent variables, differing only in dependent variable and statistical technique used. The first method utilized simple summative indices as the dependent variable in a series of multiple regression equations. Summation indices were calculated by simply summing number of behaviors in which the participant met recommended criteria, as defined by the action or maintenance stage post-intervention. To rule out potential confounds, several demographic covariates were also run, including age, gender, treatment condition, baseline stage of change, and which of the three primary studies a participant was in. Age, pre-intervention severity, and postintervention severity were continuous variables. Gender, ethnic group, treatment condition, study, and baseline stage of change were run as dummy-coded categorical variables. In addition, interactions of the two independent variables, baseline severity $\mathrm{x}$ treatment condition were examined. Both multiple regression equations in which a normal distribution is assumed and Poisson regression equations were run. It was predicted that, consistent with previous studies (Carlson et al., 2012; Drake et al., 2013; Kobayashi, 2012) this method would show statistically significant effects but relatively small effect sizes compared to other methods (see Table 1).

Z-score methods were also used. Post intervention severity scores were analyzed as the dependent variable in multiple regression equations. The independent variable under consideration was pre-intervention (baseline) severity. To rule out potential confounds, several demographic covariates were also run, including age, gender, treatment condition, baseline stage of change, and which of the three primary 
studies a participant was in. Age, pre-intervention severity, and post-intervention severity were continuous variables. Gender, racial group, treatment condition, study, and baseline stage of change were run as dummy-coded categorical variables. In addition, interactions of the two independent variables, baseline severity $\mathrm{x}$ treatment condition were examined. Z-scores were expected to show statistically significant results and account for more of the variance than the summative index method (see Table 1).

The next set of analyses used sum of standardized residuals as a dependent variable. Sum of standardized residuals is an alternate multivariate method similar to Z-scores (Carlson et al., 2012; Kobayashi, 2012; Kobayashi et al., 2014). Standardized residual were calculated via a series of multiple linear regression models with postintervention scores as dependent variables and baseline scores as independent variables. Each behavioral residual was calculated separately and then the individual standardized residual change scores were summed to create a composite. Composite standardized residual scores were run as the dependent variable in a series of multiple regression equations. For independent variables, the same covariates included in the zscore method were included in this method. Kobayashi (2014) found this method to be more sensitive to intervention effects than z-scores and it was anticipated that similar results would be found in this study, as evidenced by higher $\mathrm{R}^{2}$ values. It was further anticipated that, consistent with prior research, those participants with a better preintervention profile will show better post-intervention outcomes (see Table 1).

The optimal linear combination method was examined via a series of discriminant function analysis equations. The same independent variables were 
included as predictors. Two dependent variables were used: the number of postintervention behaviors for which a person was still at risk or in other words had not yet progressed to the action or maintenance stage and the number of stages in which they have made progress, even if it did not reach desired criteria. This method served as an alternative to the already established multivariate measurement method of multivariate analysis of variance (MANOVAs) because previous results have found that Manovas account for very little of the variance (Kobayashi, 2012). It was anticipated that, similar to previous research, those participants who showed a better initial profile would show better post-intervention outcomes. Discriminant function analysis is not well-suited to categorical predictor variables. However dichotomous variables may theoretically be included, similar to in multiple regression equations. Therefore, the dummy-coded demographic variables were run (see Table 1).

An alternative method specific to the TTM was to measure progress through the stages of change. Stage of change progress was also measured. For this method, the five stages of change were assigned numeric values, as previously described and composite stage of change scores calculated for both pre and post-intervention severity. The resulting composites were then run in a series of multiple regression equations, similar to the procedure used for $\mathrm{z}$-score examination. The same predictor covariates shall be used. Consistent with previous results, this method was anticipated to account for more of the variance than z-score or standardized residual methods (Kobayashi, 2012). It was also anticipated that those participants who show a healthier initial profile would show better post-intervention results (see Table 1). 
Previous research utilizing datasets derived from these studies to investigate the same behavioral dyads found a combined meta-analytic effect size of $h=0.28$ $(95 \%$ CI $0.24,0.32)$ for the difference in paired action rates between treatment and control groups (Yin et al., 2013). While these outcomes are substantially different from those used in this study, they represent best available estimates of possible effect sizes. Based upon this prior research and conservative estimates from Cohen's guidelines for small multivariate effects (Cohen, 1992; Rossi, 2013), estimates of required sample size to achieve power exceeding the $1-\beta=.80$ level were run. Preliminary analyses showed that each behavioral dyad required an $N=485$. Our subsamples were substantially greater than this, indicating adequate power. Analyses were considered statistically significant at the $\alpha=.05$ level. Selection of the preferred method was determined via the $R^{2}$ effect size, or in other words which method accounted for the maximum amount of variance. 


\section{RESULTS}

\section{Preliminary Analyses. Analyses were run on SPSS 19.0 and SAS 9.3.}

Consistent with prior studies using the same data, the overall sample for all three studies was primarily female, married, Caucasian, and in good or very good health. Ages ranged from 18.75 to 76 years $(M=44.34 ; S D=10.50)$ (see Table 2). Sample size came $\mathrm{N}=4197$ participants who had completed the baseline, 12 month, and 24 month time-points. Of this total sample, $25.5 \%$ completed one behavior, $60.9 \%$ completed two behaviors and $13.5 \%$ completed all three behaviors. At baseline, $18.8 \%$ of the total sample completed the smoking intervention, $69.2 \%$ completed the sun intervention, and $100 \%$ completed the diet intervention. At the 24 month time-point, $18.6 \%$ completed the smoking assessment, $67.7 \%$ completed the sun behavior assessment, and $98.6 \%$ completed the dietary behavior assessment. Stages of change, both at baseline and at 24 months are shown in Tables 3 and 4 . Descriptive statistics for the dependent variables were also calculated (see Table 5). Number of cigarettes smoked per day showed notable skew and kurtosis, unsurprising given that the majority of the sample was nonsmokers but there were several participants who smoked heavily, creating a large, positively skewed range. All other dependent variables showed signs of statistical normality, as indicated by skew and kurtosis. Linearity was examined via simple scatterplots of baseline vs. 24 month values on the dependent variables. With the exception of a few outliers, the assumption of linearity appeared to have been upheld. Correlations among the major demographic, independent, and dependent variables were also calculated (see Table 6). While there are many other statistically significant relationships, particularly among the baseline 
and 24 month scores for each of the three behaviors, none of these relationships are so high that multicollinearity should be a concern (Harlow, 2014).

Comparisons across studies were made via one-way ANOVAs and chi square tests. For gender, there was a significant difference found across the three studies, $\chi^{2}(2, N=4181)=217.037, p<.001, \varphi=.228$. The worksite study contained a greater proportion of males than either the parent study or the patient, while the parent and patient studies contained a greater proportion of female participants (Table 2).

There was also a significant difference found across studies for self-reported health status, $\chi^{2}(8, N=4180)=53.396, p<.001, \varphi=.113$. Specifically, the parent study contained a greater proportion of participants who reported their health as excellent or very good and the patient study contained a greater proportion of participants who rated their health as only good or fair. The three studies contained similar proportions of participants who rated their health as poor (Table 2).

There were also significant differences found across the three studies for marital status, $\chi^{2}(10, \mathrm{~N}=4175)=117.598, p<.001, \varphi=.168$. The parent contained a greater proportion of participants who were married compared to the patient study and the worksite study. The worksite study contained a greater proportion of participants who were living with a partner compared to the parent study and the patient study. The parent study contained a lesser proportion of participants who were not married compared to the worksite study and the patient study. The parent study also contained a greater proportion of participants who were separated than the patient study and the worksite study. The patient study contained a greater proportion of participants who 
were widowed than the parent or worksite study. The parent study contained a greater proportion of participants who were divorced compared to the other studies (Table 2).

Significant differences were found across the studies for race/ethnicity, $\chi^{2}(12$, $\mathrm{N}=4178)=46.360, p<.001, \varphi=.105$. The parent study contained a greater proportion of participants who identified as Caucasian or African-American compared to the patient and worksite study. The patient study contained a lesser proportion of Asian-American participants than the parent or worksite study. The worksite study contained a greater proportion of Hispanic participants than the other two studies (Table 2).

Significant differences in age were also found across studies, $F(2,4166)=$ $20.147, p<.001$. Levene's test was $F(2,4166)=345.717, \eta^{2}=0.0096, p<.001$, indicating significant differences in homogeneity of variance across samples. Participants in the patient study were older $(M=45.19 ; S D=12.25)$ (range 18.75 to 76.00 years) compared to those in the parent group $(M=42.85 ; S D=5.18)$ (range 19.37 to 62.16 years) or worksite group, $(M=43.69 ; S D=9.70)$ (range 20.65 to 66.24 years).

Differences were also calculated across studies based upon baseline stage of change. For diet, stage of change did not differ significantly across studies, $\chi^{2}(4, N=$ $4197)=6.011, p=.198, \varphi=.038, p=.198$. For baseline smoking, stage of change differed significantly across studies, $\chi^{2}(4, \mathrm{~N}=790)=17.450, p<.01, \varphi=.149, p<$ .01 . The parent and worksite studies contained a greater proportion of smokers in the precontemplation stage of change compared to the patient study. The patient study 
contained a greater proportion of smokers in the contemplation or preparation stages of change (Table 3$)$.

Significant differences across study were also noted for baseline sun protection stage of change, $\chi^{2}(4, \mathrm{~N}=2903)=16.540, p<.01, \varphi=.075, p<.01$. The worksite study contained a greater proportion of participants in the contemplation stage of change than the two other studies (Table 3). Overall these results indicated that there are statistically significant differences in baseline demographics and stage of change across the three studies. However this was consistent with results of prior studies (Blissmer et al., 2010) and did not suggest anything which may influence the overall results of this study.

A comparison of the dependent variables at baseline was also conducted. Given that there were very different subsample sizes, varying based on the behavior and study, heterogeneity of variance was of especial concern (Harlow, 2014). Therefore, homogeneity of variance was calculated via Levene's tests as part of examining differences across the three initial samples. It was found that there was no significant difference in baseline number of cigarettes smoked per day, $F(2,903)=$ $.453, p=.636$. Levene's test came to $F(2,903)=.402, p=.669$, indicating adequate homogeneity of variance across studies. Total scores on DBQ scores did differ significantly across studies, $F(2,4194)=3.683, p<.05$. Specifically, those participants in the worksite study had significantly lower baseline DBQ scores $(M=$ 71.66; $S D=11.63)(95 \%$ CI 70.79 to 72.53$)$ compared to participants in the parent $(M$ $=73.03 ; S D=11.28)(95 \%$ CI 72.36 to 73.70$)$ and patient studies $(M=72.94 ; S D=$ 11.68) (95\% CI 72.47 to 73.40$)$. Levene's test did not indicate significant 
heterogeneity of variance $F(2,4194)=1.342, p=.262$. For baseline sun protection scores, no significant difference was found across studies, $F(2,2900)=2.200, p=$ .111. Levene's test of homogeneity indicated that there may be significant differences in homogeneity of variance across studies $F(2,2900)=3.147, p<.05$. Collectively these results indicated that, in general, homogeneity of variance across studies is adequate, although the sun protection scores were borderline heterogeneous. There were significant differences across studies in baseline dietary behavior. However the absolute differences between scores, as identified by the $95 \%$ confidence intervals, were sufficiently small to suggest that combination of data across studies should not unduly influence the results of this study.

For the whole sample, missing data was analyzed by comparing the baseline scores of those who had complete data for all three time-points with those who had missing data at either 12 or 24 months. It was found that number of cigarettes per day did not differ significantly between these two groups, $F(1,1714)=.410, \eta^{2}=.00024$ $p=.522$. There were however significant differences in baseline DBQ scores between those who had completed all three time-points and those who had not, $F(1,6618)=$ 68.459, $\eta^{2}=0.01, p<.001$. Participants with complete data had higher baseline DBQ scores $(M=72.70 ; S D=11.60)(95 \%$ CI 72.35 to 73.05$)$ compared to those with missing data $(M=70.20 ; S D=12.28)(95 \%$ CI 69.70 to 70.69$)$. There was also a significant difference found between completers and drop-outs in baseline sun protection behavior, $F(1,4637)=26.84, \eta^{2}=.0058, p<.001$. Those who completed all three time-points had higher baseline sun protection scores $(M=20.82 ; S D=5.10)$ (95\% CI 20.64 to 21.01$)$ than those who dropped out $(M=19.99 ; S D=5.57)(95 \% \mathrm{CI}$ 
19.73 to 20.25$)$. These overall results indicate that those who completed the study had healthier initial profiles. It must be noted however that the absolute differences between completers and non-completers is very small, often within a single point. 95\% confidence intervals and small effect sizes indicate substantial overlap between these scores. This indicates that, while the problem is missing data is noteworthy and should not be readily dismissed, its impact upon overall results may be minimal.

\section{Single Behavior Analyses.}

The reliability of single behavior analyses was done via a series of multiple regression equations for each individual behavior. The dependent variables consisted of composite SPBS scores at 24 months, total DBQ scores at 24 months, and number of cigarettes per day at 24 months. The independent variables consisted of total SPBS scores at baseline, total DBQ scores at baseline, and number of cigarettes per day at baseline. Each baseline independent variable was run in separate equation with the corresponding dependent variable.

A series of covariates were also run, including age, gender, treatment condition, and baseline SOC. The categorical variables were dummy-coded according to the procedures outlined by Cohen, Cohen, West, and Aiken (2003). For the study group variable, parent study was used as the reference group. For the baseline stage of change variable, precontemplation was used as the reference group. The reference groups for the dichotomous covariates were male (gender covariate), control group (treatment condition), and Caucasian-American (ethnicity/race) (Table 9). 
For dietary behavior, there was a significant effect of baseline severity, as operationalized by total DBQ scores, on to total DBQ scores at 24 months, $F(1,4150)$ $=3287.87, p<.001, \beta=.66, R^{2}=.44$. There was also an overall significant effect of the covariates $, F(8,4114)=58.89, p<.001, R^{2}=.10$. Specifically, there were statistically significant effects found for age $(\beta=.12, p<.001)$, gender $(\beta=.22, p<$ $.001)$, ethnicity $(\beta=.-.08, p<.001)$ treatment condition $(\beta=.15, p<.001)$, the patient study $(\beta=-.05, p<.01)$, and diet preparation stage of change $(\beta=.10, p<.001)$. Effects not reaching statistical significance were found for the worksite study $(\beta$ $=.0009, p=.96)$ and the diet contemplation stage of change $(\beta=0.02, p=.12)$. In other words, participants with better post-intervention outcomes were more likely to be older, female, Caucasian, in the treatment condition, in the preparation stage of change, not in the patient study, and have better dietary practices when the study began.

Total dietary behavior scores were next run with the previously described covariates. An overall statistically significant effect was found $F(10,4112)=358.55$, $p<.001, R^{2}=0.47$. Specific effects were found for baseline dietary behavior $(\beta=.63$, $p<.001)$, age $(\beta=0.04, p<.01)$, gender $(\beta=0.08, p<.001)$, the patient study $(\beta=-$ $0.05, p<.001)$, diet preparation stage $(\beta=0.03, p<.05)$, and ethnicity $(\beta=-0.04, p<$ $.01)$. Effects not reaching statistical significance were found for treatment condition $(\beta$ $=0.08, p=.26)$, worksite study $(\beta=-0.005, p=.73)$, diet contemplation stage of change ( $\beta=0.02, p=.15)$, and the interaction of baseline severity and treatment condition $(\beta=0.04, p=.61)$. Participants with better post-intervention outcomes were 
more likely to be older, female, Caucasian, in the preparation stage of change, and not in the patient study.

Smoking was examined in a similar fashion, with reverse scored number of cigarettes per day at 24 months as post-intervention severity and reverse scored number of cigarettes per day at baseline as baseline severity. A significant effect of baseline severity on post-intervention severity was found, $F(1,814)=231.55, p<$ $.001, \beta=.47, R^{2}=.22$. The overall impact of the collective covariates upon postintervention severity did not reach statistical significance, $F(8,706)=1.72, p=0.09$, $R^{2}=0.02$. Significant effects were found for age $(\beta=-0.07, p<.05)$ and smoking preparation stage of change $(\beta=0.09, p<.05)$. Non-significant effects were found for gender $(\beta=0.05, p=.17)$, ethnicity $(\beta=0.03, p=0.42)$, treatment condition $(\beta=0.03$, $p=.36)$, patient study $(\beta=0.03, p=.51)$, worksite study $(\beta=0.07, p=.11)$, and smoking contemplation stage of change $(\beta=0.05, p=.27)$. Although not significant overall, these results suggest that post-intervention success was more likely for participants who were younger, in the preparation stage of change, and smoked less before the intervention.

The baseline variables were next run with the covariates. The overall effect was significant, $F(10,703)=20.93, p<.001, R^{2}=.23$. Baseline severity was a significant predictor $(\beta=.46, p<.001)$. None of the other covariates were statistically significant including age $(\beta=-0.03, p=.39)$, gender $(\beta=-0.02, p=.50)$, treatment condition $(\beta=0.05, p=.48)$, patient study $(\beta=0.03, p=.45)$, worksite study $(\beta=$ $0.04, p=.29)$, smoking contemplation stage of change $(\beta=0.04, p=.31)$, smoking preparation stage of change $(\beta=0.01, p=.79)$, baseline severity $\mathrm{x}$ treatment condition 
interaction $(\beta=0.06, p=.44)$ and race/ethnicity $(\beta=0.009, p=.78)$. Because none of the covariates reached statistical significance and their regression coefficients were so small, it appears that age, gender, ethnicity, treatment condition, and study had no impact upon whether participants were able to quit smoking.

Sun protection behavior was regressed in a similar fashion, with baseline severity defined as total SPBS scores at baseline and post-intervention severity defined as post-intervention SPBS scores. There was a significant effect of baseline severity on post-intervention severity, $F(1,2847)=1930.99, p<.001, \beta=.64, R^{2}=0.40$. A statistically significant effect was also found for the collective covariates, $F(8,2827)=$ 109.46, $p<.001, R^{2}=.24$. Significant effects were found for gender $(\beta=0.16, p<$ $.001)$, ethnicity $(\beta=-0.03, p<.05)$, treatment condition $(\beta=.13, p<.001)$, sun contemplation stage of change $(\beta=.19, p<.001)$, and sun preparation stage of change $(\beta=.49, p<.001)$. Effects not reaching significance were found for age $(\beta=.02, p$ $=.33)$, patient study $(\beta=-0.04, p=.07)$ and worksite study $(\beta=0.02, p=.36)$. Participants were more likely to show post-intervention success if they were female, Caucasian, in the treatment condition, had progressed past the precontemplation stage of change and already used more sun protection methods pre-intervention.

An overall significant effect was also found when baseline severity and baseline severity $\mathrm{x}$ treatment condition were added to the covariates An overall significant effect was found $F(10,2825)=216.50, p<.001, R^{2}=0.43$. Significant effects were found for baseline severity $(\beta=.58, p<.001)$, as well as age $(\beta=0.03, p$ $<.05)$, gender $(\beta=0.09, p<.001)$, patient study $(\beta=-0.04, p<.05)$, sun contemplation stage of change $(\beta=0.09, p<.001)$, and sun preparation stage of 
change $(\beta=0.08, p<.001)$. Effects not reaching statistical significance were found for treatment condition $(\beta=.11, p=.06)$, worksite study $(\beta=0.01, p=.40)$, baseline severity $\mathrm{x}$ treatment condition $(\beta=0.008, p=.90)$, and race/ethnicity $(\beta=-0.002, p=$ .89). Participants were more likely to be successful if they were older, female, in the parent study, had progressed past the precontemplation stage of change, and were already using sun protection methods before the intervention.

\section{Summative Indices: Multiple Regression}

Preliminary results examined the distribution of participates either meeting or not meeting desired criteria for each of the three behaviors, both individually and in pairs (see Tables 7 and 8). Summative indices scores for behavioral pairs were defined as reaching the action or maintenance stage in each of the three behaviors. Summative scores could be zero, one or two behaviors (see Table 8). A small percentage of participants reached desired criteria on both behaviors post-intervention, and the majority did not reach desired criteria on either behavior.

Summative indices were first run as the dependent variable in a series of multiple regression equations in which a normal Gaussian distribution was assumed. All participants had not reached action or maintenance criteria on either behavior preintervention. Therefore, number of pre-intervention behaviors reaching desired criteria equaled zero for all participants and could not add information on baseline severity. This was countered by running two alternate sets of equations with plausible baseline predictor variables. The first set of equations used baseline composite stage of change, as well as the previously described set of covariates, including age, gender, ethnicity, 
treatment condition, patient study, and worksite study. The second set of equations ran the same covariates, plus the previously described standardized composite severity score and the standardized severity $\mathrm{x}$ treatment condition interaction. Because the summative index outcome variable is a count variable with a narrow range, summative indices were also analyzed as the dependent variable in a series of multiple regression equations with a Poisson distribution

For smoking and sun protection behavior, there was a statistically significant overall effect, $F(7,533)=10.76, p<.001, R^{2}=0.1238$. Statistically significant effects were found for treatment condition, baseline composite stage of change, and ethnicity. Effects not reaching statistical significance were found for age, gender, patient study condition, and worksite study condition (Table 10). Successful participants tended to be in the treatment condition, Caucasian, and further along on the stages of change.

The next set of analyses ran the same predictors via Poisson regression. For smoking and sun protection, there was not an overall significant effect $\chi^{2}(533)=$ 436.90, $p=.999, \log$ likelihood $=-350.12, \mathrm{AIC}=737.03$. Significant effects were found for treatment condition and baseline stage of change. Ethnicity approached statistical significance. Parameters not reaching statistical significance included age, gender, patient study, and worksite study (Table 11). Participants were more likely to successfully change their behavior if they were Caucasian, in the treatment condition and already further along on the stages of change.

There was also an overall significant effect for smoking and diet behavior, $F(7$, $752)=3.89, \mathrm{p}<.001, R^{2}=0.0349$. Statistically significant effects were found for 
treatment condition and baseline composite stage of change. Effects not reaching significance were found for age, gender, patient study condition, worksite study condition, and ethnicity (Table 12). Participants were more likely to successfully change their behavior if they were in the treatment condition and were further advanced on the stages of change.

For smoking and diet, there was not an overall significant result $\chi^{2}(752)=$ 624.52, $p=1.0, \log$ likelihood $=-551.61$, AIC $=1159.42$. Significant effects were found for treatment condition and baseline stage of change. Parameters not reaching significance were found for age, gender, patient study, worksite study, and ethnicity (Table 13). Participants were more successful if they were in the treatment condition and more advanced in the stages of change at baseline.

Sun protection and diet behavior also continued to show an overall significant effect, $F(7,2773)=38.45, p<.001, R^{2}=0.0885$. Significant effects were found for age, gender, treatment condition, patient study, and composite baseline stage of change. Effects not reaching statistical significance were found for worksite study and ethnicity (Table 14). Participants were more likely to succeed if they were older, female, in the treatment condition, not in the patient study, and more advanced on the stages of change at baseline.

For sun protection and diet behavior there was an overall significant effect $\chi^{2}$ $(2773)=2343.42, p=1.0, \log$ likelihood $=-1904.65$, AIC $=4001.36$. Significant effects were found for age, gender, treatment condition, patient study, and baseline stage of change. Effects not reaching significance were found for worksite study and 
ethnicity (Table 15). Participants were more likely to successfully change if they were older, female, in the treatment condition, not in the patient study, and more advanced along the stages of change at baseline.

Summative Indices: with standardized severity

The next set of equations ran the same set of covariates, as well as composite standardized baseline severity, and the standardized baseline severity $\mathrm{x}$ treatment condition interaction. For sun protection behavior and smoking, an overall significant effect was found $F(9,503)=9.19, p<.001, R^{2}=0.1413$. Significant effects were found for treatment condition and composite baseline stage of change. Effects not reaching significance were found for age, gender, patient study, worksite study, composite standardized baseline severity, baseline severity $\mathrm{x}$ treatment condition interaction and ethnicity (Table 16). Participants were more likely to successfully change if they were in the treatment condition and more advanced along the stages of change at baseline.

The last set of equations with summative indices used the covariates of age, gender, treatment condition, patient study, worksite study, baseline stage of change, standardized baseline severity, baseline severity $\mathrm{x}$ treatment interaction, and ethnicity. For smoking and sun protection, there was not an overall significant effect $\chi^{2}(503)=$ 403.70, $p=0.99959, \log$ likelihood $=-326.57, \mathrm{AIC}=692.55$. Significant effects were found for baseline stage of change and standardized baseline severity. Effects not reaching significance were found for age, gender, treatment condition, patient study, worksite study, baseline severity $\mathrm{x}$ treatment condition, and ethnicity (Table 17). 
Those who changed their behavior tended to be more advanced along the stages of change, smoke less, and have better sun protection habits at baseline.

There was also an overall significant effect for smoking and diet, $F(9,713)=$ $7.30, p<.001, R^{2}=0.0843$. Significant effects were found for composite baseline stage of change and composite standardized baseline severity. Effects not reaching significance were found for age, gender, treatment condition, patient study, worksite study, baseline severity $\mathrm{x}$ treatment condition interaction, and ethnicity (Table 18). Participants who successfully changed their behavior tended to be more advanced along the stages of change, smoke less, and have better dietary habits at baseline.

For smoking and diet behavior, there was not an overall significant effect $\chi^{2}$ $(713)=593.94, p=0.99957, \log$ likelihood $=-504.80, \mathrm{AIC}=1068.42$. Standardized baseline severity was significant. Age, gender, treatment condition, patient study, worksite study, baseline stage of change, baseline severity $\mathrm{x}$ treatment interaction, and ethnicity were all non-significant (Table 19). Participants who successfully changed their behavior tended to smoke less and have better diets at baseline.

There was also an overall significant effect for sun protection and diet, $F(9$, 2771) $=56.09, p<.001, R^{2}=0.1541$. Significant effects were found for gender, treatment condition, patient study, composite baseline stage of change, composite standardized baseline severity, and baseline severity $\mathrm{x}$ treatment condition interaction. Effects not reaching significance were found for age, worksite study, and ethnicity (Table 20). Participants tended to be female, in the treatment condition, not in the patient study, be further advanced along the stages of change at baseline, have better 
diets and sun protection habits at baseline, especially if they were in both the treatment condition and advanced along the stages of change.

For sun protection and diet behavior there was an overall significant effect $\chi^{2}$ $(2771)=2222.83, p=1.0, \log$ likelihood $=-1811.60, \mathrm{AIC}=3819.25$. Significant effects were found for gender, treatment condition, patient study, baseline stage of change, and standardized baseline severity. Effects not reaching significance were found for age, worksite study, severity $\mathrm{x}$ treatment interaction, and ethnicity (Table 21). Participants were more likely to succeed in the intervention if they were female, in the treatment condition, not in the patient study, be farther along the stages of change at baseline, and had better sun and diet habits at baseline.

\section{Z-Scores}

The next analytic method consisted of z-scores. Similar to summative indices, a series of multiple regression equations were run. The independent variables consisted of the same covariates, age, gender, ethnicity, treatment condition, patient study, worksite study, and composite baseline stage of change. The main predictor was the previously described standardized composite baseline severity score. Treatment condition $\mathrm{x}$ standardized baseline severity interaction was also run. The dependent variable was standardized composite post-intervention scores, calculated the same as pre-intervention scores.

For smoking and sun protection, there was an overall significant effect $F(9$, $495)=42.51, p<.001, R^{2}=0.4359$. Significant effects were found gender, baseline stage of change, standardized baseline severity, and ethnicity. Effects not reaching 
significance were found for age, patient study, worksite study, and standardized severity $\mathrm{x}$ treatment stage of change interaction (Table 22). Participants who successfully changed their behavior tended to be female, Caucasian, be more advanced along the stages of change and have better smoking and sun protection habits at baseline.

For smoking and diet behavior, there was an overall significant effect $F(9$, $696)=53.87, p<.001, R^{2}=0.4106$. Significant effects were found for gender, treatment condition, baseline standardized severity, and ethnicity. Effects not reaching significance were found for age, patient study, worksite study, baseline stage of change, and standardized severity x treatment condition interaction (Table 23). Participants who successfully changed their behavior tended to be female, Caucasian, in the treatment condition, smoke less and have better diet at baseline.

For diet behavior and sun protection, there was an overall significant effect $F(9,2792)=317.18, p<.001, R^{2}=0.5055$. Significant effects were found for age, gender, treatment condition, patient study, baseline stage of change, and standardized baseline severity. Effects not reaching significance were found for worksite study, standardized severity $\mathrm{x}$ treatment condition, and ethnicity (Table 24). Successful participants tended to be older, female, in the treatment condition, not in the patient study, be further along the stages of change at baseline, and have better diet and sun protection habits at baseline.

\section{Standardized Residuals}


The next set of equations ran in a very similar fashion to z-scores. A series of multiple regression equations were run. The same covariates of age, gender, ethnicity, treatment condition, patient study, worksite study, baseline stage of change, and standardized severity $\mathrm{x}$ treatment condition interaction were used. The main predictor was standardized baseline severity.

The dependent variable was standardized residual scores calculated according to the procedures outlined by Kobayashi (2012), Carlston and colleagues (2012), and Prochaska, Velicer et al. (2008b). Baseline severity scores for each individual behavior were regressed onto post-intervention severity scores to give standardized residual scores. While cigarettes per day was reverse scored, no other transformations were used on baseline and post-intervention scores. This lead to a score standardized with a mean of zero and a standard deviation of one (Carlston et al., 2012; Tucker, Damarin, \& Messick, 1966; Veldman \& Brophy, 1974) (see Table 25). Standardized residuals from individual behaviors were summed to form composite pairs (Carlston et al., 2012). Slight negative skew and notable kurtosis was found for the smoking variable (Table 25).

For smoking and sun protection, there was an overall significant effect $F(9$, $495)=1.99, p<0.05, R^{2}=0.0349$. None of the predictors showed a statistically significant effect, although gender and ethnicity approached significance. Nonsignificant effects were found for age, treatment condition, patient study, worksite study, baseline stage of change, standardized baseline severity and standardized severity $\mathrm{x}$ treatment condition interaction (see Table 26). Participants tended to show better post-intervention results if they were female and Caucasian. 
For smoking and diet behavior, there was an overall significant effect $F(9$, 696) $=2.19, p<0.05, R^{2}=0.0275$. Significant effects were found for gender and treatment condition. Effects not reaching significance were found for age, patient study, worksite study, baseline stage of change, standardized baseline severity and standardized severity $\mathrm{x}$ treatment condition interaction (see Table 27). Participants tended to succeed if they were female and in the treatment condition.

For diet and sun protection, there was an overall significant effect $F(9,2792)$ $=21.06, p<0.001, R^{2}=0.0636$. Significant effects were found for age, gender, treatment condition, patient study, and baseline stage of change. Effects not reaching significance were found for worksite study, standardized baseline severity, standardized severity $\mathrm{x}$ treatment condition interaction, and ethnicity (see Table 28). Participants who succeeded tended be older, female, in the treatment condition, not in the patient study, and be more advanced along the stages of change at baseline.

\section{Discriminant Function Analysis: Summative Indices}

The next set of analyses consisted of a series of discriminant function analyses (DFA). Previous studies have found that multivariate analysis of variance (MANOVA) may be used as a multiple health behavior change measurement method. However it accounts for relatively little variance (Kobayashi, 2012) and may not be well-suited towards variables with low correlation between the dependent variables. Therefore DFA, which is mathematically equivalent to MANOVA, was suggested as an alternative (Kobayashi, 2012). 
DFA may also not be ideally suited to all MHBC studies. The dependent variables must be categorical and independent variables are usually continuous (Harlow, 2014). DFA was run twice, once with summative indices, or the number of behaviors reaching desired criteria post-intervention (zero, one, or two), and once using composite post-intervention stage of change, which allowed for measuring progress not reaching desired criteria. The same predictor variables were run, including age, gender, ethnicity, treatment condition, patient study, worksite study, baseline stage of change, standardized baseline severity, and standardized severity $\mathrm{x}$ treatment condition interaction. Categorical variables were dummy-coded, as described in previous analyses. Because discriminant loadings do not have significance tests, loadings exceeding $|0.3|$ were considered meaningful (Harlow, 2014). It was recognized that due to unequal group sizes among the outcome variable and the categorical nature of several predictor variables, DFA may not be ideally suited to this type of analysis.

The first set of analyses used summative indices as the dependent variable. For smoking and sun protection, there remained an overall significant effect and a medium effect size (see Table 29). Of the two linear combinations, only the first was statistically significant $F(18,1004)=p<.001$, eigenvalue $=0.1657$, canonical correlation $=.3770$. The discriminant loadings were meaningful for treatment condition, baseline stage of change, and standardized severity $\mathrm{x}$ treatment condition interaction (see Table 30). Classification error rates came to .4771 , indicating a correct classification of $52.29 \%$. 
For smoking and diet summative indices, there was an overall significant effect and a small to medium effect size (Cohen, 1992) (see Table 31). Of the two linear combinations only the first was statistically significant, $F(18,1424)=4.14, p<.001$, eigenvalue $=0.0939$, canonical correlation $=.2929$. The discriminant loadings were meaningful for treatment condition and standardized baseline severity (see Table 32). Classification error rates came to .5120 , indicating a correct classification of $48.80 \%$.

For sun protection and diet summative indices, there was also an overall significant effect including a medium effect size (see Table 33). The first linear combination was statistically significant, $F(18,5540)=27.94, p<.001$, eigenvalue $=$ 0.1833 , canonical correlation $=.3935$, while the second linear combination approached statistical significance, $F(8,2771)=1.91, p=.054$, eigenvalue $=0.0055$, canonical correlation $=.3935$. Meaningful discriminant loadings were found for treatment condition, standardized baseline severity and standardized severity $\mathrm{x}$ treatment condition interaction. (see Table 34). Error classification rates came to .4834 , indicating a correct classification rate of $51.66 \%$.

\section{Discriminant Function Analysis: Stage of Change}

The next set of analyses used post-intervention stage of change as the dependent variable. Stage of change was defined as $1=$ precontemplation, $2=$ contemplation, $3=$ preparation, $4=$ action, and $5=$ maintenance. Final postintervention stage of change for each behavior was summed for form a composite score, providing more detailed information than post-intervention summation scores. The same set of predictor variables was used. 
For smoking and sun protection, there was an overall significant effect including a large effect size (see Table 35). Of the eight linear combinations only the first was statistically significant $F(72,3024.6)=3.33, p<.001$, eigenvalue $=0.3796$, canonical correlation $=.52457$. Of the discriminant loadings, treatment condition, baseline stage of change, and standardized baseline severity (see Table 36). Error classification rate came to .6803 . Correct classification rate came to $31.97 \%$.

For diet behavior and smoking, there was an overall significant effect including a large effect size (see Table 37). Of the eight linear combinations, the first was statistically significant $F(72,4302)=3.03, p<.001$, eigenvalue $=0.2306$, canonical correlation $=.4328$. Meaningful discriminant loadings were found for baseline stage of change and standardized baseline severity (see Table 38). The error classification rate came to .7567 , indicating a correct classification rate of $24.33 \%$.

For diet behavior and sun protection, there was an overall significant effect including a large effect size (see Table 39). Of the eight linear combinations, the first $F(72,16820)=14.29, p<.001$, eigenvalue $=0.3672$, canonical correlation $=.51822$ and second $F(56,14895)=2.40, p<.001$, eigenvalue $=0.0284$, canonical correlation $=.1661$ were statistically significant. For the first combination, meaningful discriminant loadings were found for treatment condition, baseline stage of change, and standardized baseline severity (see Table 40). The error classification rate came to .7491 , indicating a successful classification rate of $25.09 \%$.

Post-Intervention Stage of Change 
The final set of analyses proceeded similarly to summative indices. A series of multiple regression equations were run. The dependent predictor consisted of composite post-intervention stage of change, also known as composite baseline stage of change. Post-intervention stage of change composites could range from two to ten with a mean score of 4.4 or 4.60. Skew and kurtosis were within acceptable range (see Tables 41 and 42). This allowed for greater detail, including accounting for intervention progress which did reach desired criteria. The independent predictors included the same covariates of age, gender, ethnicity, treatment condition, patient study, worksite study, and composite baseline stage of change. Equations were run once with only these covariates, using composite baseline stage of change as a measure of baseline severity, calculated identically to post-intervention severity. Equations were next run these predictors and inclusion of standardized baseline severity and standardized severity $\mathrm{x}$ treatment condition interaction, to ensure consistency with prior analyses.

For smoking and sun protection there was an overall significant effect $F(7$, $533)=24.61, p<.001, R^{2}=.2443$. Significant effects were found for treatment condition and baseline stage of change. Effects not reaching significance were found for age, gender, patient condition, worksite condition, and ethnicity (see Table 43). Successful participants tended to be in the treatment condition and more advanced along the stages of change at baseline.

There was also an overall significant effect for smoking and diet, $F(7,752)=$ $14.58, p<.001, R^{2}=.1195$. Specifically, there were significant main effects for treatment condition and composite baseline stage of change. Effects not reaching 
significance were found for age, gender, patient study, worksite study, and ethnicity (see Table 44). Participants who succeeded in the intervention tended to be in the treatment condition and be more advanced along the stages of change at baseline.

There was also an overall significant effect for diet and sun protection, $F(7$, $2773)=88.33, p<.001, R^{2}=.1823$. Significant effects were found for age, gender, treatment condition, patient study and baseline stage of change. Effects not reaching significance were found for worksite study and ethnicity (see Table 45). Participants who successfully changed their behavior tended to be older, female, in the treatment condition, not in the patient study, and be more advanced along the stages of change at baseline.

Post-Intervention Stage of Change with Standardized Severity

The next set of analyses included the same set of covariates in addition to standardized baseline severity and standardized severity $\mathrm{x}$ treatment condition interaction. For smoking and sun protection, there was an overall significant effect, $F(9,503)=20.70, p<.001, R^{2}=.2703$. Significant effects were found for baseline stage of change and standardized baseline severity. Effects not reaching significance were found for age, gender, treatment condition, patient study, worksite study, standardized severity $\mathrm{x}$ treatment condition interaction, and ethnicity (see Table 46). Participants who changed their behavior tended to be more advanced along the stages of change at baseline, smoke less, and have better sun protection habits at baseline.

For smoking and diet behavior, there was an overall significant effect $F(9$, $713)=15.02, p<.001, R^{2}=.1594$. Significant main effects were found for baseline 
stage of change and standardized baseline severity. Effects not reaching statistical significance were found for age, gender, treatment condition, patient study, worksite study, standardized severity $\mathrm{x}$ treatment condition interaction, and ethnicity (see Table 47). Participants who changed their behavior tended to be more advanced along the stages of change, smoke less, and have better diets before intervention.

Lastly, for sun protection and diet there was an overall significant effect, $F(9$, $2771)=106.61, p<.001, R^{2}=.2572$. Significant main effects gender, treatment condition, patient study, baseline stage of change, standardized baseline severity, standardized severity $\mathrm{x}$ treatment condition, and ethnicity. Effects not reaching significance were found for age and worksite study (see Table 48). Participants who successfully changed their behavior tended to be female, an ethnic minority, in the treatment condition, not in the patient study, be more advanced along the stages of change at baseline, have better diet or sun protection habits at baseline. This was especially so if participants were both in the treatment condition and had better habits at baseline. A summary of effect size measures for each analytic strategy is presented in Table 49 


\section{DISCUSSION}

Summary of Analyses

The main purpose of this study was to investigate which analytic method produced the best measure of effect, as evidenced by the most inclusive effect size. All analytic methods included the same set of independent variables. Two statistical techniques, multiple regression and discriminant function analysis, were used. The main difference was either the presence or absence of standardized baseline severity scores and the choice of dependent variable.

A comparison of effect sizes for all analytic methods demonstrates that the most inclusive methods tended to be those which allowed for the most detail. For all three behavioral combinations, $\mathrm{z}$-scores resulted in the greatest amount of variance accounted for. This was followed by composite post-intervention stage of change scores, analyzed either via discriminant function analysis or multiple regression. This is consistent with previous results which demonstrated that less detailed measures such as summative indices did not perform as well compared to methods allowing greater variation.

Z-scores showed the greatest amount of variance accounted for and has several inherent advantages. Z-scores are widely understood and popular. Standardized baseline severity is in itself a z-score transformation, which allows for consistency between baseline predictors and outcomes. Furthermore z-scores are by necessity transformed continuous variables, making them well applicable to regressions and therefore more comparable to other studies. 
Summative indices are a universally popular method and were analyzed with four different methods: with and without standardized severity and with either multiple regression with a normal distribution assumed or with Poisson regression. Consistent with other analyses, including standardized severity greatly increased the amount of variance accounted for. It was also noteworthy that approximately similar results were found whether a normal Gaussian or Poisson distribution was assumed. This suggests that, despite some violations of statistical assumptions, researchers may be able to obtain meaningful results using simple multiple regression. Using multiple regression may have its own set of advantages. Multiple regression is a more commonly employed method and therefore results of a study utilizing this method may be more readily compared to other results in the literature. Furthermore the effect size, $\mathrm{R}^{2}$, is readily calculated with multiple regression. McFadden's pseudo $\mathrm{R}^{2}$ is conceptually a comparison of a null model with a full model, indicating that its purpose is not amount of variance accounted for but instead model comparison, a different purpose than usual effect sizes. Therefore McFadden's pseudo $\mathrm{R}^{2}$ is not readily comparable to either $\mathrm{R}^{2}$ or other effect sizes and has less practical utility.

Interestingly, standardized residuals performed rather poorly, accounting for less variance than other methods, despite showing superior results to summative indices (Carlson et al., 2012) and z-scores (Kobayashi 2012) in past studies. An examination of methods reveals a few fundamental differences. To begin, this study and Kobayashi (2012) did find rather similar overall effect sizes, as specified by $\mathrm{R}^{2}$ values. However Kobayashi (2012) found small effect sizes for z-scores while this study found larger ones. Kobayashi (2012) used square root transformations on 
smoking data to counter non-normality, while this study found that unnecessary once certain smoking scores which could not be properly classified were excluded. The two sets of analyses in which smoking was included either did not reach or barely reached statistical significance, possibly due to sample size, since few participants were smokers. Additionally, Kobayashi (2012) examined only one predictor, treatment vs. control. This study chose to utilize a variety of demographic and baseline severity measures, as would typically be seen in an intervention outcome study. While these additional measurements might not explain the low effect size of standardized residuals, they might help explain why alternative measures showed larger overall effect sizes.

Because this study and previous ones have shown such varying conclusions about standardized residuals, more studies might be necessary to determine under which conditions this method is most useful. Carlson et al. (2012) similarly compared standardized residuals with summative indices and found a stronger intervention effect for standardized residuals. Perhaps however, this study was more similar in aim to Kobayashi (2012) because both were examining specifically the effect of the intervention, rather than the effect of baseline severity. Furthermore severity measures are built into the calculation of standardized residuals, perhaps meaning that this method is inappropriate as a way of measuring severity and is better suited towards examining other covariates.

Discriminant function analysis (DFA) performed rather well. Indeed, compared to the mathematically equivalent MANOVA which past studies have shown to perform rather poorly (Kobayashi, 2012), DFA accounted for a fair amount of 
variance. This was especially so when the dependent variable was the more detailed composite stage of change rather than a summative index. Whether DFA can be said to be the most appropriate technique for $\mathrm{MHBC}$ is an interesting question since this method made use of several categorical variables, dummy-coded in a manner typical of multiple regression. Because DFA is not used in the literature to the same extent as regression, whether these results violate DFA's statistical assumptions must be further investigated. Furthermore, DFA does not provide beta weights for each variable, but instead canonical correlations, which may make this method less useful to future studies wishing to examine the impact of specific variables. There is also the manner of which dependent variable to use. Summative indices are simpler to compute and easier to comprehend. The resulting canonical correlations are more readily interpreted. However once composite stage of change is used, although the overall results are superior, the intricate pattern of canonical correlations makes examining the impact of individual independent variables difficult. This difficulty is likely to compound further if behavioral triplets were used rather than pairs. Therefore DFA, while showing promise, is recommended to be used with caution.

The last set of analyses utilized post-intervention stage of change as the dependent variable. This analysis essentially used the post-intervention equivalent of the pre-intervention composite stage of change. This method also performed well, better than standardized residuals and summative indices although not as well as zscores. Multiple regression was used and although post-intervention stage of change is technically a count variable, the variable was found to mimic a normal curve sufficiently that it could be treated as a continuous variable. Use of regression allowed 
for use of $\mathrm{R}^{2}$ effect size as well as continuous and dummy-coded predictor variables, making it a good overall method. However, post-intervention stage of change is inherently dependent upon the transtheoretical model. While this model is broad in scope and has been found to apply to many behaviors (Hall \& Rossi, 2008), there are many other interventions which may wish to utilize MHBC measurements. In those cases, an alternative method, such as z-scores might be necessary.

A few trends were noted among the independent variables also. These analyses utilized the same set of covariates, age, gender, treatment condition, primary study and baseline stage of change, differing only on the presence or absence of standardized baseline severity and standardized baseline severity $\mathrm{x}$ treatment condition interaction. Standardized baseline severity added a large amount of variance, almost invariably leading to a large multivariate effect size (Cohen, 1992). Furthermore, the interaction term of baseline severity and treatment condition was rarely statistically significant. In addition, the other measure of pre-intervention severity, composite baseline severity, was also often statistically significant even amongst smaller samples and remained significant with the addition of standardized baseline severity. Severity appears to be a stronger predictor of post-intervention success than any of the covariates, including treatment condition.

That is not to say that the covariates did not provide intriguing information. Treatment condition was frequently statistically significant if the sample size was large or only the demographic covariates were used. Fortunate, as practitioners would hope their intervention would meaningfully impact behavior. Just as notable, treatment condition was often not statistically significant if standardized baseline severity was 
included as an independent variable. Treatment condition was a stronger predictor of treatment success than the demographic variables. This may be partly due to this variable being a dummy-coded comparison with other continuous variables such as standardized severity, being more suited to multiple regression comparison. Taken at face value, this further highlights that post-intervention severity is more strongly influenced by pre-intervention severity and stage of change compared to treatment condition. In other words how prepared a person is to make a healthy lifestyle change is more determinant of their success than whether or not they receive an intervention. As has often been shown in the literature and clinical practice, interventions given to those who are unready or in an earlier stage of change in which they are unprepared for meaningful action will have little effect.

Curiously the interaction effect of standardized severity and treatment condition was also rarely statistically significant, even with a large sample size. One would intuitively suspect that persons who are ready for behavior change might most strongly respond to an intervention designed to help them change their behavior. This was not the case. Perhaps once a person has decided on their own to make lifestyle changes, they will seek out resources that will help them make changes on their own, regardless of what interventions are available. It is further possible that those who were in the control condition but were already close to desired criteria, sought out ways to improve their behavior without prompting from the researcher. The very act of being in a health behavior study might have provided sufficient motivation for an already motivated subgroup. 
The statistical significance of age and gender tended to vary based upon sample size, indicating that while these may have some effects, they tended to be less important than other variables. Usually when the demographic covariates were statistically significant, participants showed better post-intervention outcomes if they were older, female, and Caucasian. However for each of these trends there was at least one analysis in which better outcomes were found if the participants were younger, male or from an ethnic minority. Overall this highlights that when designing interventions for certain behavioral combinations, those interventions should be tailored to certain subsamples which may respond differently.

Overall, the independent variables were consistent with prior studies. Statistical significance tended to vary based upon sample size, with variables being much more likely to be statistically significant in the larger subsample of sun protection and diet behavior. In smaller samples, the demographic covariates tended to show non-significant or small effects, consistent with prior studies showing that demographic effects were inconsistent or small (Blissmer et al., 2010). This was especially so in comparison to more malleable concerns such as baseline stage of change and baseline severity.

\section{Limitations and Future Directions}

There are other variables which researchers may wish to examine in future studies. It was determined that baseline severity and the calculated change indices were so highly correlated that they could not be included in the same analyses. Therefore amount of change was excluded as a possible independent variable. Other 
variables which this study did not examine include level of effort. This could be measured via the transtheoretical model's processes of change, decisional balance, self-efficacy, and temptation constructs, which might show significant effects between level of effort, post-intervention success and level of change.

The previous methods examined MHBC at the individual level. Another method, the expanded intervention impact score, is based upon an intervention's total effect upon the general population (Drake et al., 2013) via the intervention impact formula of intervention impact $=$ efficacy times participation $(I=E \times P)($ Velicer \& Prochaska, 1999). The formula could be expanded to include multiple behaviors $(\mathrm{I}=\Sigma$ number of behaviors (n) (En x Pn) (Prochaska, Velicer et al., 2008b), where P is the proportion of individuals who are at risk for each behavior, and E is the estimated efficacy of intervention for each behavior, defined as the percentage of participants meeting recommended guidelines at follow-up. However, because this is a populationbased measure, it cannot be used to examine the impact of baseline severity upon individual outcomes and was unsuitable for this study. Future studies interested in MHBC at the population level may wish to utilize this method.

There are a few further limitations which future research may wish to consider. Only three cancer-prevention behaviors were considered and those behaviors were examined in pairs. There are other behaviors worth consideration, such as exercise, compliance with prescribed medication regimes, and responsible alcohol intake. Behaviors may also be modified in triplets or even with four or more behaviors. It is currently unknown if there is a maximum number of behaviors which may be simultaneously modified. The increase both in potentially modifiable behaviors and 
behavioral combinations leads to the question of which behaviors are best changed together. Past studies of behavioral pairs have found that change organized around an intuitive theme, such as healthy energy balance with diet and exercise, showed greater effect sizes than those behaviors which are less obviously linked, such as smoking and sun protection (Yin et al., 2013). There may also be behaviors which do not lend themselves as well to MHBC. Behavioral pairs involving smoking for example have been found to show comparatively smaller effect sizes (Yin et al., 2013). These results are in conflict with the findings of this study which showed that the two behavioral pairs involving smoking have similar effect sizes to sun and diet. Broad results cannot be drawn from such a narrow comparison however and it is worth exploring which behavioral combinations product the greatest overall behavior change.

Behaviors may also be aimed at reducing the risks of other illnesses, such as diabetes or heart disease. These behaviors have growing prevalence rates, similar to cancer and tend to have risk factors similar to cancer. Interventions with the aim of promoting general as well as illness-specific health have the potential to greatly improve public health.

Furthermore this study was comprised of primary prevention data from persons who are not ill. Research has shown that cancer survivors, far from having more careful health behavior, show comparably high rates of risk behaviors such as smoking, diet and risky sun protection behavior. Indeed younger cancer survivors are more likely to smoke than non-cancer controls (Coups \& Ostroff, 2005). Yet health behavior change during treatment or to prevent remission is now considered a key part of cancer treatment (Demark-Wahnefried, 2005; Pinto \& Trunzo, 2005). Studies are 
currently underway to determine optimal ways to encourage healthy behavior change in cancer survivors. Encouraging multiple healthy behaviors amongst this population certainly has a place and great potential for improved public health.

Sample Limitations. Additionally, despite its large size, this sample was relatively homogenous. The lack of racial/ethnic diversity is of particular concern, as previous studies have shown that differences in health-related behaviors tend to vary along ethnic lines (Buller et al., 2011; Trinidad et al., 2011). Ideally, ethnicity would be included in the study as a moderating variable so that its independent influence and effect size could be considered. However a few practical limitations precluded this. The sample was overwhelmingly Caucasian. The subsample sizes were so unbalanced that any independent effects of ethnicity could not be found. Indeed, ethnicity was rarely found to be statistically significant, even when the sample was so strongly powered that other normally non-significant effects, such as patient or worksite study, were statistically significant. Furthermore because ethnicity groups were so uneven, at best, ethnicity could only be dichotomized as Caucasian vs. ethnic minority. This meant that minority groups such as African-American, Asian-American, Native American, Hispanic, and multiracial were all lumped together even though there is certain to be considerable differences in health concerns and health behavior across these groups. Because the purpose of this study was to evaluate methodologies rather than to evaluate an intervention or describe health-related behaviors, these limitations did not negatively impact the overall findings. However future studies with different aims should take these difficulties into consideration by selecting a more diverse sample. 
There were a few other limits in generalizability. Females outnumbered males in the study. Most participants were middle-aged. The samples were recruited from the northeastern United States. Results may not generalize to people from different geographic regions. Senior citizens and children have different health concerns than middle-aged adults, which would be reflected in different health behaviors. Additionally the majority of participants reported good health. In $200045 \%$ of the American public had a chronic health condition with $21 \%$ having multiple chronic conditions. These numbers are projected to grow over the next several decades (Anderson \& Horvath, 2004). Therefore this relatively healthy sample may be less than representative of the general public.

Female participants were usually shown to have better habits than males. On the surface this might reflect a greater health awareness or concern among females. It might also reflect the behaviors. Women tend to more concerned with sun protection (Weinstock et al., 2000) and diets compared with men (Dehghan, Akhtar-Danesh, \& Merchant, 2011). Although clinical samples have generally shown men to have higher success rates with quitting smoking, other studies using the general population disagree and say neither gender is more likely to quit smoking (Jarvis et al., 2013). In other words, for two of the three behaviors, women tend to perform better than men and the third behavior shows comparable gender rates. Men may be more inclined towards other behaviors such as exercise adoption (Loprinzi \& Cardinal, 2012).

Methodological Limitations. Because the primary purpose of this study was to establish a multivariate methodology for health behavior change research, several methodological limits must be addressed. To begin with, only three behaviors were 
studied and those behaviors studied in pairs. This was deliberately done so that pairs, the most basic unit of multiple health behavior change, might first be examined. There is as yet no theoretical reason why pairs should behave differently than three or more behaviors. However this has not yet been established.

There were also differences in how desired criteria were determined. Smoking cessation had a clearly defined public health guideline which participants strove towards, namely zero cigarettes per day. Dietary behavior was measured via the DBQ and sun protection via the SPBS. Desired criteria scores were determined by examining the average scores of persons meeting either action or maintenance stage of change post-intervention. Therefore the exact 'desired criteria' scores for this study will differ from cut-off scores for different studies.

The variability of public health guidelines must also be considered. At the time of data collection, excessive dietary fat intake was regarded as a risk factor for chronic illness. Since then research has shifted from quantity to quality. Certain types of fats are currently shown to have protective effects against illnesses such as cancer (Schwab et al., 2014; Zheng et al., 2013). Therefore, public health guidelines on total dietary fat have given way to varied recommendations based upon type of fat and individual health needs. Similarly, while general public health recommendations endorse five servings of fruit and vegetables per day, nutrition guidelines vary based upon age, health status, activity level, etc. (USDA \& USDHHS, 2010). It is therefore difficult to set an exact desired criterion applicable to everyone. Likewise with sun protection, there is not an exact desired outcome. Indeed, sun protection can be achieved several different ways, such as avoiding excessive sun exposure or by 
wearing protective clothing and sunblock. This underscores that there is variety in determining desired outcome. Since desired outcome is necessary to compute severity and especially z-scores, finding a method to best determine how far a person needs to go in an intervention is especially important.

Smoking has an advantage over diet and sun protection in that there is an unambiguous public health goal, complete cessation. There is also an easy to measure behavior, cigarettes per day. A disadvantage is that this method relies upon a single item measure. Single item measures are widely reported as less reliable than scales (Wanous \& Hudy, 2001) although some studies indicate they perform comparably (Ginns \& Barrie, 2004). Smoking behavior showed notable skew and kurtosis. Most people, even those who smoke and have no immediate plans to quit, are aware of the health risks (Hammond et al., 2006). Heavy smokers are rare and the rate of heavy smoking is decreasing (Jamal et al., 2014). This leads to a positive skew, with most participants smoking few cigarettes and a few heavy smokers. Such data violates the statistical assumptions inherent in most analyses, including multiple regression and discriminant function analysis. Transformations or the removal of outliers can often be used to correct the problem (Kobayashi, 2012; Osbourne \& Water, 2002). In this way, behaviors which are measured via scales rather than single items have an advantage in terms of statistical robustness. Yet as previously mentioned, scale measures have the inherent problem of finding a cut-off point that corresponds to recommended public health guidelines, since public health guidelines favor the simplicity of single item measures. This study attempted to find a middle ground, using a single-item measure for smoking and scale scores for diet and sun protection. Desired criteria on scales 
might be determined several ways. This study determined who reached desired criteria by using average scores of those participants reaching action or maintenance stage. Some scale may have a built in cut-off score. Other options can include expert determination of cut-offs, such as answering a certain way on a certain number of items in each subscale. Essentially, before multivariate measurement may be attempted, each single behavior must have a valid method of determining desired outcomes which can be readily convertible to a standardized score suitable for combination with other standardized scores.

Another practical consideration is finding a method that corresponds to statistical requirements of each analytic method. Both multiple regression and discriminant function analysis favor continuous predictor variables. One favors continuous outcome variables and one favors categorical variables. Both have stringent statistical assumptions (Harlow, 2014). Because regression has the option of dummy-coding as a method of handling categorical predictor variables and has multiple methods for handling slight violations of statistical assumptions, is much more ubiquitous, and easy to use, multiple regression may be a preferred method over discriminant function analysis.

This study used complete case analysis, excluding those participants who did not provide complete data or could not be classified into one of the primary studies. Comparisons of the study indicated that baseline differences between participants who completed the intervention and those who dropped out or provided incomplete data tended to be minimal or nonexistent. Because the study's main purpose was methodological rather than descriptive, these differences did not detract from the 
overall results. However future research may wish to utilize more advanced missing data techniques such as multiple imputation. This may also strengthen the case for multiple regression as a favored $\mathrm{MHBC}$ method, there are quite a few multiple imputation methods specialized for regression (Graham, 2012) and relatively fewer options for DFA.

This study demonstrated that persons with better baseline scores tend to have the best post-intervention outcomes. There are several practical implications to this finding. Persons who are closer to their goal are more likely to ultimately achieve it. This is rather similar to the basic tenant of the transtheoretical model that those who are most advanced along the stages of change are those most likely to successfully change their behavior. Interventions until now have been based upon baseline stage of change rather than amount of severity. However this study shows that baseline severity is good predictor of intervention success, at least as much as baseline stage of change. Future interventions may wish to tailor their strategies based upon not only stage of change and processes of change but also level of severity and amount of change necessary to transition into the action or maintenance stage.

Despite these limitations, this study had several valuable strengths. Three pairs of behaviors, including two adoption behaviors and one cessation behavior were examined with consistent results. The study successfully replicated much of the previous research, while also discovering several areas ripe for future research. Crossmethods comparisons were made with the same set of predictor variables, such that any differences in effect size might be definitively attributed to how the dependent variable was calculated. 
In summary, this study examined several different methods for measuring multiple health behavior change in a primary cancer prevention intervention. Standardized measures of baseline severity were examined as a primary predictor. Overall results found that multiple health behavior change methods which allow for greater detail, such as z-scores and movement through the stages of change, account for a greater amount of variance than simpler methods such as summative indices. Standardized residuals do not appear to be well-suited towards research in which standardized severity is a primary predictor variable. Given the ease of use and ubiquity of multiple regression, this method may be preferred over the more esoteric discriminant function analysis. 


\section{TABLES}

Table 1

Analytic Strategies for Multiple Health Behavior Change

\begin{tabular}{llcc}
\hline Analytic Strategy & Statistic & \multicolumn{2}{c}{ With Standardized Severity } \\
& & Yes & No \\
\hline Summative Index & Linear Regression & $\mathrm{X}$ & $\mathrm{X}$ \\
& Poisson Regression & $\mathrm{X}$ & $\mathrm{X}$ \\
& Discriminant Function Analysis & $\mathrm{X}$ & \\
Z-Scores & Linear Regression & $\mathrm{X}$ & \\
Standardized & Linear Regression & $\mathrm{X}$ & \\
Residuals & & & \\
Stage of Change & Discriminant Function Analysis & $\mathrm{X}$ & \\
Progress & & & $\mathrm{X}$ \\
& Linear Regression & $\mathrm{X}$ & \\
\hline
\end{tabular}


Table 2

Descriptive Statistics for Total Sample

\begin{tabular}{|c|c|c|c|c|c|c|}
\hline & & Frequency & Total & Parent & Patient & Worksite \\
\hline & & & Sample & $\mathrm{N}=1083$ & $\mathrm{~N}=2416$ & $\mathrm{~N}=682$ \\
\hline \multirow[t]{2}{*}{ Gender } & Male & 1489 & $35.6 \%$ & $26.9 \%$ & $32.7 \%$ & $59.7 \%$ \\
\hline & Female & 2692 & $64.4 \%$ & $73.1 \%$ & $67.3 \%$ & $40.3 \%$ \\
\hline \multirow[t]{5}{*}{ Health } & Poor & 51 & $1.2 \%$ & $1.2 \%$ & $1.2 \%$ & $1.2 \%$ \\
\hline & Fair & 473 & $11.3 \%$ & $7.6 \%$ & $12.1 \%$ & $14.4 \%$ \\
\hline & Good & 1640 & $39.2 \%$ & $34.8 \%$ & $41.1 \%$ & $39.6 \%$ \\
\hline & Very Good & 1513 & $36.2 \%$ & $41.3 \%$ & $35.0 \%$ & $32.3 \%$ \\
\hline & Excellent & 503 & $12.0 \%$ & $15.1 \%$ & $10.5 \%$ & $12.6 \%$ \\
\hline \multirow[t]{9}{*}{ Ethnicity } & White & 3971 & $95.0 \%$ & $93.3 \%$ & $96.4 \%$ & $93.1 \%$ \\
\hline & Black & 51 & $1.2 \%$ & $1.9 \%$ & $.8 \%$ & $1.6 \%$ \\
\hline & Asian/ Pacific & 29 & $.7 \%$ & $.9 \%$ & $.3 \%$ & $1.8 \%$ \\
\hline & Islander & & & & & \\
\hline & American & 19 & $.5 \%$ & $.6 \%$ & $.4 \%$ & $.4 \%$ \\
\hline & Indian & & & & & \\
\hline & Hispanic & 38 & $.9 \%$ & $.7 \%$ & $.7 \%$ & $1.8 \%$ \\
\hline & Combination & 37 & $.9 \%$ & $1.7 \%$ & $.6 \%$ & $.7 \%$ \\
\hline & Other & 33 & $.8 \%$ & $.7 \%$ & $.9 \%$ & $.6 \%$ \\
\hline
\end{tabular}




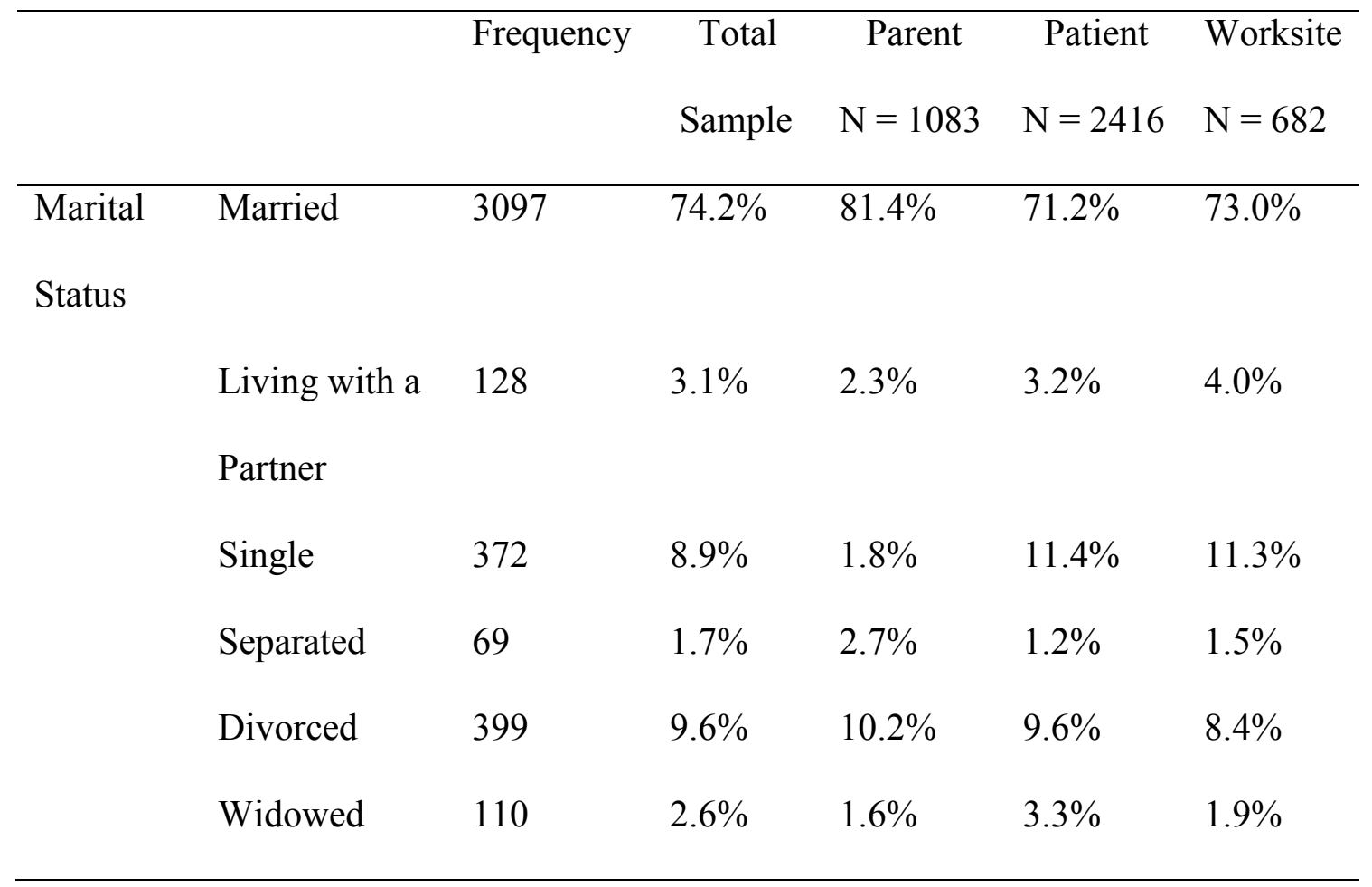


Table 3

Stage of Change at Baseline

\begin{tabular}{|c|c|c|c|c|c|c|}
\hline Behavior & Stage & Frequency & $\begin{array}{l}\text { Percentage } \\
(\mathrm{N}=4197)\end{array}$ & $\begin{array}{l}\text { Parent } \\
(\mathrm{N}=1096)\end{array}$ & $\begin{array}{l}\text { Patient } \\
(\mathrm{N}=2417)\end{array}$ & $\begin{array}{l}\text { Worksite } \\
(\mathrm{N}=684)\end{array}$ \\
\hline \multirow[t]{3}{*}{ Diet } & $\mathrm{PC}$ & 2195 & $52.3 \%$ & $54.2 \%$ & $52.3 \%$ & $49.4 \%$ \\
\hline & $\mathrm{C}$ & 619 & $14.7 \%$ & $14.6 \%$ & $14.2 \%$ & $17.0 \%$ \\
\hline & PR & 1383 & $33.0 \%$ & $31.2 \%$ & $33.6 \%$ & $33.6 \%$ \\
\hline \multirow[t]{3}{*}{ Smoking } & $\mathrm{PC}$ & 276 & $34.9 \%$ & $41.9 \%$ & $29.3 \%$ & $44.1 \%$ \\
\hline & $\mathrm{C}$ & 350 & $44.3 \%$ & $42.3 \%$ & $47.6 \%$ & $34.3 \%$ \\
\hline & PR & 164 & $20.8 \%$ & $15.8 \%$ & $23.1 \%$ & $21.6 \%$ \\
\hline \multirow[t]{3}{*}{ Sun } & $\mathrm{PC}$ & 998 & $34.4 \%$ & $35.0 \%$ & $34.9 \%$ & $31.8 \%$ \\
\hline & $\mathrm{C}$ & 659 & $22.7 \%$ & $19.4 \%$ & $22.3 \%$ & $29.0 \%$ \\
\hline & PR & 1246 & $42.9 \%$ & $45.6 \%$ & $42.8 \%$ & $39.2 \%$ \\
\hline
\end{tabular}


Table 4

Stage of Change at 24 month time-point

\begin{tabular}{|c|c|c|c|c|c|c|}
\hline Behavior & Stage & Frequency & Percentage & Parent & Patient & Worksite \\
\hline \multirow[t]{5}{*}{ Diet } & $\mathrm{PC}$ & 1812 & $43.8 \%$ & $45.0 \%$ & $42.8 \%$ & $45.2 \%$ \\
\hline & $\mathrm{C}$ & 658 & $15.9 \%$ & $14.2 \%$ & $17.3 \%$ & $13.7 \%$ \\
\hline & PR & 834 & $20.2 \%$ & $19.4 \%$ & $20.7 \%$ & $19.3 \%$ \\
\hline & A & 196 & $4.7 \%$ & $5.5 \%$ & $4.7 \%$ & $3.6 \%$ \\
\hline & M & 638 & $15.4 \%$ & $15.8 \%$ & $14.5 \%$ & $18.2 \%$ \\
\hline \multirow[t]{5}{*}{ Smoking } & $\mathrm{PC}$ & 238 & $30.4 \%$ & $35.5 \%$ & $27.1 \%$ & $34.0 \%$ \\
\hline & $\mathrm{C}$ & 272 & $34.8 \%$ & $34.6 \%$ & $34.8 \%$ & $35.0 \%$ \\
\hline & PR & 111 & $14.2 \%$ & $9.1 \%$ & $17.3 \%$ & $12.0 \%$ \\
\hline & A & 136 & $17.4 \%$ & $17.3 \%$ & $17.7 \%$ & $16.0 \%$ \\
\hline & M & 25 & $3.2 \%$ & $3.5 \%$ & $3.1 \%$ & $3.0 \%$ \\
\hline \multirow[t]{5}{*}{ Sun } & $\mathrm{PC}$ & 1066 & $37.5 \%$ & $34.2 \%$ & $39.0 \%$ & $37.2 \%$ \\
\hline & $\mathrm{C}$ & 409 & $14.4 \%$ & $11.2 \%$ & $15.9 \%$ & $14.2 \%$ \\
\hline & PR & 867 & $30.5 \%$ & $33.5 \%$ & $29.1 \%$ & $30.9 \%$ \\
\hline & A & 21 & $.7 \%$ & $1.1 \%$ & $.6 \%$ & $.6 \%$ \\
\hline & M & 480 & $16.9 \%$ & $20.1 \%$ & $15.4 \%$ & $17.1 \%$ \\
\hline
\end{tabular}


Table 5

Descriptive Statistics of the dependent variables

\begin{tabular}{lccccccc}
\hline & $\mathrm{N}$ & Min & Max & Mean & SD & Skew & Kurtosis \\
\hline $\begin{array}{l}\text { Cigarettes/ day } \\
\text { (BL) }\end{array}$ & 906 & 0 & 80.0 & 18.52 & 10.42 & 1.07 & 2.53 \\
$\begin{array}{l}\text { Cigarettes/ day } \\
\text { (24) }\end{array}$ & 817 & 0 & 88 & 16.05 & 13.44 & 1.22 & 3.04 \\
Cigarettes/ day & 906 & -80.00 & .00 & -18.52 & 10.42 & -1.07 & 2.53 \\
(BL) R & & & & & & & \\
Cigarettes/ day & 817 & -88.00 & .00 & -16.05 & 13.44 & -1.22 & 3.04 \\
$\begin{array}{l}\text { (24) R } \\
\text { DBQ (BL) }\end{array}$ & 4197 & 29.00 & 106.00 & 72.75 & 11.57 & -.37 & -.04 \\
DBQ (24) & 4152 & 4.00 & 109.00 & 74.94 & 12.72 & -.33 & .20 \\
SPBS (BL) & 2903 & 1.00 & 34.00 & 20.83 & 5.09 & -.58 & -.18 \\
SPBS (24) & 2849 & 7.00 & 35.00 & 22.48 & 5.73 & -.32 & -.26 \\
\hline
\end{tabular}


Table 6

Correlations between baseline and post-intervention scores of 3 behaviors

\begin{tabular}{|c|c|c|c|c|c|c|}
\hline & $\begin{array}{l}\text { DBQ } \\
(B L)\end{array}$ & $\begin{array}{l}\text { DBQ } \\
(24)\end{array}$ & $\begin{array}{l}\text { SPBS } \\
(\mathrm{BL})\end{array}$ & $\begin{array}{l}\text { SPBS } \\
(24)\end{array}$ & $\begin{array}{c}\text { Cig/ Day } \\
\text { (BL) }\end{array}$ & $\begin{array}{l}\text { Cig/ } \\
\text { Day } \\
(24)\end{array}$ \\
\hline $\begin{array}{l}\text { DBQ } \\
(B L)\end{array}$ & 1 & $.665^{* *}$ & $.234^{* *}$ & $.217^{* *}$ & $-.161^{* *}$ & $-.133^{* *}$ \\
\hline $\begin{array}{l}\text { DBQ } \\
(24)\end{array}$ & $.665^{* *}$ & 1 & $.206^{* *}$ & $.286^{* *}$ & $-.112^{* *}$ & $-.133^{* *}$ \\
\hline $\begin{array}{l}\text { SPBS } \\
(\mathrm{BL})\end{array}$ & $.234^{* *}$ & $.206^{* *}$ & 1 & $.636^{* *}$ & $-.139^{* *}$ & $-.213^{* *}$ \\
\hline $\begin{array}{l}\text { SPBS } \\
(24)\end{array}$ & $.217^{* *}$ & $.286^{* *}$ & $.636^{* *}$ & 1 & $-.095^{*}$ & $-.173^{* *}$ \\
\hline $\begin{array}{l}\text { Cig/ Day } \\
(\mathrm{BL})\end{array}$ & $-.161^{* *}$ & $-.112^{* *}$ & $-.139^{* *}$ & $-.095^{*}$ & 1 & $.471^{* *}$ \\
\hline $\begin{array}{l}\text { Cig/ Day } \\
\text { (24) }\end{array}$ & $-.133^{* *}$ & $-.133^{* *}$ & $-.213^{* *}$ & $-.173^{* *}$ & $.471^{* *}$ & 1 \\
\hline
\end{tabular}


Table 7

Distribution of Participants Reaching Desired Criteria Post-Intervention, single behaviors

\begin{tabular}{llll}
\hline & & N & Percentage \\
\hline Smoking & Does not meet criteria & 621 & $79.4 \%$ \\
& Meets Criteria & 161 & $20.6 \%$ \\
Sun & Does not meet criteria & 2342 & $82.4 \%$ \\
& Meets Criteria & 501 & $17.6 \%$ \\
Diet & Does not meet criteria & 3304 & $79.8 \%$ \\
& & 834 & $20.2 \%$ \\
& Meets criteria & & \\
& &
\end{tabular}


Table 8

Distribution of Participants meeting criteria post-intervention, behavioral pairs

\begin{tabular}{llll}
\hline & & N & Percentage \\
\hline Smoking \& Sun & Meets criteria 0 & 378 & $69.5 \%$ \\
& Meets criteria 1 & 151 & $27.8 \%$ \\
Smoking \& Diet & Meets criteria 2 & 15 & $2.8 \%$ \\
& Meets criteria 0 & 511 & $66.7 \%$ \\
& Meets criteria 1 & 226 & $29.5 \%$ \\
Sun \& Diet & Meets criteria 2 & 29 & $3.8 \%$ \\
& Meets criteria 0 & 1923 & $68.8 \%$ \\
& Meets criteria 1 & 743 & $26.6 \%$ \\
& Meets criteria 2 & 128 & $4.6 \%$ \\
\hline
\end{tabular}


Table 9

Dummy Coding Scheme for Categorical Variables in Multiple Regression

\begin{tabular}{lcc}
\hline Variable & Reference & Other \\
\hline Gender & Male & Female \\
Ethnicity & Caucasian & Minority \\
Intervention & Control & Treatment \\
Study & Parent & Patient \\
Study & Parent & Worksite \\
Baseline stage of change & Precontemplation & Contemplation \\
Baseline stage of change & Precontemplation & Preparation \\
\hline
\end{tabular}


Table 10

Summative index, Multiple regression, sun and smoking, without standardized severity

\begin{tabular}{lccccc}
\hline & B & $\begin{array}{c}\text { Standard } \\
\text { Error }\end{array}$ & t Value & $p$ & $\beta$ \\
\hline Age & 0.0017 & 0.0022 & 0.78 & 0.434 & 0.032 \\
Gender & 0.058 & 0.045 & 1.29 & 0.197 & 0.054 \\
Ethnicity & -0.240 & 0.102 & -2.35 & 0.019 & -0.096 \\
Treatment condition & 0.161 & 0.044 & 3.64 & 0.0003 & 0.149 \\
Patient study & -0.039 & 0.050 & -0.78 & 0.436 & -0.036 \\
Worksite study & -0.023 & 0.074 & -0.32 & 0.752 & -0.015 \\
Baseline SOC & 0.133 & 0.018 & 7.45 & $<.0001$ & 0.304 \\
\hline
\end{tabular}


Table 11

Summative index, Poisson regression, smoking and sun protection, without standardized severity

\begin{tabular}{lcccccc}
\hline & Estimate & $\begin{array}{c}\text { Standard } \\
\text { Error }\end{array}$ & \multicolumn{2}{c}{$\begin{array}{c}\text { Wald 95\% } \\
\text { Confidence Limits }\end{array}$} & $\begin{array}{c}\text { Wald Chi- } \\
\text { Square }\end{array}$ & Pr > ChiSq \\
\hline Age & 0.0046 & 0.0076 & -0.010 & 0.020 & 0.36 & 0.546 \\
Gender & 0.163 & 0.161 & -0.152 & 0.478 & 1.03 & 0.310 \\
Ethnicity & -0.988 & 0.509 & -1.985 & 0.0087 & 3.77 & 0.052 \\
$\begin{array}{l}\text { Treatment } \\
\text { condition }\end{array}$ & 0.463 & 0.150 & 0.169 & 0.757 & 9.52 & 0.0020 \\
$\begin{array}{l}\text { Patient study } \\
\text { Worksite }\end{array}$ & -0.130 & 0.171 & -0.465 & 0.204 & 0.58 & 0.446 \\
$\begin{array}{l}\text { study } \\
\text { Baseline }\end{array}$ & -0.058 & 0.265 & -0.577 & 0.461 & 0.05 & 0.826 \\
SOC & 0.400 & 0.063 & 0.276 & 0.524 & 39.96 & $<.0001$ \\
\hline
\end{tabular}


Table 12

Summative index, Multiple regression, smoking and diet, without standardized severity

\begin{tabular}{lccccc}
\hline & $\mathrm{B}$ & $\begin{array}{c}\text { Standard } \\
\text { Error }\end{array}$ & $\mathrm{t}$ Value & $\mathrm{p}$ & $\beta$ \\
\hline Age & -0.000056 & 0.0021 & -0.03 & 0.979 & -0.00098 \\
Gender & 0.030 & 0.043 & 0.70 & 0.484 & 0.026 \\
Ethnicity & -0.118 & 0.098 & -1.20 & 0.232 & -0.043 \\
Treatment condition & 0.121 & 0.041 & 2.93 & 0.0035 & 0.106 \\
Patient study & -0.064 & 0.046 & -1.38 & 0.170 & -0.056 \\
Worksite study & -0.0017 & 0.069 & -0.02 & 0.981 & -0.00098 \\
Baseline SOC & 0.066 & 0.017 & 3.86 & 0.0001 & 0.140 \\
\hline
\end{tabular}


Table 13

Summative index, Poisson regression, smoking and diet without standardized severity

\begin{tabular}{lcccccc}
\hline & Estimate & $\begin{array}{c}\text { Standard } \\
\text { Error }\end{array}$ & \multicolumn{2}{c}{$\begin{array}{c}\text { Wald 95\% } \\
\text { Confidence Limits }\end{array}$} & $\begin{array}{c}\text { Wald Chi- } \\
\text { Square }\end{array}$ & Pr $>$ ChiSq \\
\hline Age & -0.0002 & 0.0063 & -0.013 & 0.012 & 0.00 & 0.973 \\
Gender & 0.083 & 0.132 & -0.175 & 0.341 & 0.40 & 0.529 \\
Ethnicity & -0.338 & 0.324 & -0.972 & 0.297 & 1.09 & 0.297 \\
$\begin{array}{l}\text { Treatment } \\
\text { condition }\end{array}$ & 0.319 & 0.120 & 0.084 & 0.554 & 7.10 & 0.0077 \\
$\begin{array}{l}\text { Patient study } \\
\text { Worksite }\end{array}$ & -0.172 & 0.136 & -0.438 & 0.094 & 1.61 & 0.204 \\
study & 0.0017 & 0.201 & -0.392 & 0.395 & 0.00 & 0.993 \\
$\begin{array}{l}\text { Baseline } \\
\text { SOC }\end{array}$ & 0.174 & 0.050 & 0.077 & 0.272 & 12.23 & 0.0005 \\
\hline
\end{tabular}


Table 14

Summative Index, Multiple regression, sun and diet, without standardized severity

\begin{tabular}{lccccc}
\hline & $\mathrm{B}$ & $\begin{array}{c}\text { Standard } \\
\text { Error }\end{array}$ & $\mathrm{t}$ Value & $\mathrm{p}$ & $\beta$ \\
\hline Age & 0.0024 & 0.00100 & 2.36 & 0.018 & 0.043 \\
Gender & 0.146 & 0.022 & 6.69 & $<.0001$ & 0.127 \\
Ethnicity & -0.044 & 0.047 & -0.93 & 0.351 & -0.017 \\
Treatment condition & 0.172 & 0.021 & 8.24 & $<.0001$ & 0.150 \\
Patient study & -0.083 & 0.025 & -3.35 & 0.0008 & -0.072 \\
Worksite study & 0.011 & 0.033 & 0.34 & 0.732 & 0.0075 \\
Baseline SOC & 0.086 & 0.0079 & 10.90 & $<.0001$ & 0.200 \\
\hline
\end{tabular}


Table 15

Summative index, Poisson regression, sun and diet, without standardized severity

\begin{tabular}{lcccccc}
\hline & Estimate & $\begin{array}{c}\text { Standard } \\
\text { Error }\end{array}$ & \multicolumn{2}{c}{$\begin{array}{c}\text { Wald 95\% } \\
\text { Confidence Limits }\end{array}$} & $\begin{array}{c}\text { Wald Chi- } \\
\text { Square }\end{array}$ & Pr $>$ ChiSq \\
\hline Age & 0.0071 & 0.0031 & 0.0010 & 0.013 & 5.13 & 0.024 \\
Gender & 0.427 & 0.071 & 0.287 & 0.566 & 35.90 & $<.0001$ \\
Ethnicity & -0.154 & 0.147 & -0.442 & 0.135 & 1.09 & 0.297 \\
$\begin{array}{l}\text { Treatment } \\
\text { condition }\end{array}$ & 0.478 & 0.064 & 0.353 & 0.603 & 56.16 & $<.0001$ \\
$\begin{array}{l}\text { Patient study } \\
\text { Worksite }\end{array}$ & -0.229 & 0.074 & -0.374 & -0.084 & 9.54 & 0.0020 \\
study & 0.048 & 0.097 & -0.143 & 0.239 & 0.24 & 0.622 \\
$\begin{array}{l}\text { Baseline } \\
\text { SOC }\end{array}$ & 0.242 & 0.025 & 0.193 & 0.290 & 96.02 & $<.0001$ \\
& & & & & & \\
\hline
\end{tabular}


Table 16

Summative index, Multiple regression, sun and smoking, with standardized severity

\begin{tabular}{lccccc}
\hline & $\mathrm{B}$ & $\begin{array}{c}\text { Standard } \\
\text { Error }\end{array}$ & $\mathrm{t}$ Value & $\mathrm{p}$ & $\beta$ \\
\hline Age & 0.00081 & 0.0023 & 0.35 & 0.723 & 0.015 \\
Gender & 0.0083 & 0.047 & 0.18 & 0.861 & 0.0077 \\
Ethnicity & -0.189 & 0.105 & -1.80 & 0.073 & -0.075 \\
Treatment condition & 0.295 & 0.116 & 2.54 & 0.011 & 0.272 \\
Patient study & -0.039 & 0.051 & -0.76 & 0.447 & -0.036 \\
Worksite study & -0.023 & 0.078 & -0.30 & 0.768 & -0.014 \\
Baseline SOC & 0.100 & 0.022 & 4.59 & $<.0001$ & 0.229 \\
Standardized baseline severity & 0.036 & 0.021 & 1.73 & 0.084 & 0.105 \\
Baseline severity x treatment & 0.044 & 0.030 & 1.50 & 0.135 & 0.165 \\
condition & & & & & \\
\hline
\end{tabular}


Table 17

Summative index, Poisson regression smoking and sun, with standardized severity

\begin{tabular}{|c|c|c|c|c|c|c|}
\hline & Estimate & $\begin{array}{c}\text { Standard } \\
\text { Error }\end{array}$ & \multicolumn{2}{|c|}{$\begin{array}{c}\text { Wald 95\% } \\
\text { Confidence } \\
\text { Limits }\end{array}$} & $\begin{array}{l}\text { Wald } \\
\text { Chi- } \\
\text { Square }\end{array}$ & $\operatorname{Pr}>$ ChiSq \\
\hline Age & 0.0043 & 0.0081 & -0.012 & 0.020 & 0.28 & 0.599 \\
\hline Gender & 0.024 & 0.170 & -0.310 & 0.357 & 0.02 & 0.890 \\
\hline Ethnicity & -0.771 & 0.511 & -1.771 & 0.230 & 2.28 & 0.131 \\
\hline $\begin{array}{l}\text { Treatment } \\
\text { condition }\end{array}$ & 0.389 & 0.377 & -0.350 & 1.127 & 1.06 & 0.302 \\
\hline Patient study & -0.133 & 0.176 & -0.478 & 0.211 & 0.58 & 0.448 \\
\hline Worksite study & -0.072 & 0.283 & -0.627 & 0.483 & 0.06 & 0.800 \\
\hline Baseline SOC & 0.282 & 0.078 & 0.128 & 0.435 & 12.94 & 0.0003 \\
\hline $\begin{array}{l}\text { Standardized } \\
\text { baseline severity }\end{array}$ & 0.196 & 0.090 & 0.019 & 0.374 & 4.73 & 0.030 \\
\hline $\begin{array}{l}\text { Baseline severity } \\
\mathrm{x} \text { treatment } \\
\text { condition }\end{array}$ & 0.0020 & 0.116 & -0.224 & 0.228 & 0.00 & 0.986 \\
\hline
\end{tabular}


Table 18

Summative index, Multiple regression, smoking and diet, with standardized severity

\begin{tabular}{lccccc}
\hline & $\mathrm{B}$ & $\begin{array}{c}\text { Standard } \\
\text { Error }\end{array}$ & $\mathrm{t}$ Value & $\mathrm{p}$ & $\beta$ \\
\hline Age & -0.00078 & 0.0021 & -0.37 & 0.708 & -0.014 \\
Gender & -0.055 & 0.046 & -1.20 & 0.229 & -0.046 \\
Ethnicity & -0.091 & 0.099 & -0.91 & 0.361 & -0.033 \\
Treatment condition & 0.151 & 0.092 & 1.63 & 0.103 & 0.131 \\
Patient study & -0.050 & 0.046 & -1.08 & 0.283 & -0.044 \\
Worksite study & 0.028 & 0.071 & 0.39 & 0.699 & 0.016 \\
Baseline SOC & 0.037 & 0.018 & 2.08 & 0.038 & 0.078 \\
Standardized baseline severity & 0.084 & 0.017 & 4.80 & $<.0001$ & 0.229 \\
Baseline severity x treatment & 0.016 & 0.027 & 0.57 & 0.568 & 0.048 \\
condition & & & & & \\
\hline
\end{tabular}


Table 19

Summative index, Poisson regression smoking and diet, with standardized severity

\begin{tabular}{lcccccc}
\hline & Estimate & $\begin{array}{c}\text { Standard } \\
\text { Error }\end{array}$ & \multicolumn{2}{c}{$\begin{array}{c}\text { Wald 95\% } \\
\text { Confidence } \\
\text { Limits }\end{array}$} & $\begin{array}{c}\text { Wald } \\
\text { Chi- } \\
\text { Square }\end{array}$ & Pr > ChiSq \\
\hline Age & -0.0033 & 0.0066 & -0.016 & 0.0098 & 0.24 & 0.622 \\
Gender & -0.140 & 0.141 & -0.417 & 0.137 & 0.98 & 0.323 \\
$\begin{array}{l}\text { Ethnicity } \\
\text { Treatment }\end{array}$ & -0.273 & 0.341 & -0.942 & 0.396 & 0.64 & 0.424 \\
$\begin{array}{l}\text { condition } \\
\text { Patient study }\end{array}$ & 0.151 & 0.256 & -0.350 & 0.653 & 0.35 & 0.554 \\
$\begin{array}{l}\text { Worksite study } \\
\text { Baseline SOC }\end{array}$ & -0.131 & 0.139 & -0.404 & 0.142 & 0.88 & 0.348 \\
$\begin{array}{l}\text { Standardized } \\
\text { baseline severity }\end{array}$ & 0.090 & 0.212 & -0.312 & 0.518 & 0.24 & 0.625 \\
$\begin{array}{l}\text { Baseline severity } \\
\text { x treatment }\end{array}$ & -0.052 & 0.064 & -0.014 & 0.194 & 2.91 & 0.088 \\
condition & & 0.090 & -0.171 & 0.422 & 21.40 & $<.0001$ \\
\hline
\end{tabular}


Table 20

Summative index, Multiple regression, sun and diet, with standardized severity

\begin{tabular}{lccccc}
\hline & B & $\begin{array}{c}\text { Standard } \\
\text { Error }\end{array}$ & t Value & $p$ & $\beta$ \\
\hline Age & 0.0012 & 0.00096 & 1.19 & 0.234 & 0.021 \\
Gender & 0.075 & 0.022 & 3.48 & 0.0005 & 0.065 \\
Ethnicity & 0.019 & 0.046 & 0.42 & 0.678 & 0.0073 \\
Treatment condition & 0.296 & 0.044 & 6.75 & $<.0001$ & 0.258 \\
Patient study & -0.073 & 0.024 & -3.09 & 0.0020 & -0.064 \\
Worksite study & 0.012 & 0.032 & 0.39 & 0.694 & 0.0083 \\
Baseline SOC & 0.040 & 0.0083 & 4.84 & $<.0001$ & 0.093 \\
Standardized baseline severity & 0.083 & 0.0090 & 9.23 & $<.0001$ & 0.229 \\
Baseline severity x treatment & 0.045 & 0.013 & 3.54 & 0.0004 & 0.144 \\
condition & & & & & \\
\hline
\end{tabular}


Table 21

Summative index, Poisson regression sun and diet, with standardized severity

\begin{tabular}{|c|c|c|c|c|c|c|}
\hline & Estimate & $\begin{array}{c}\text { Standard } \\
\text { Error }\end{array}$ & $\begin{array}{l}\text { Walc } \\
\text { Confider }\end{array}$ & $\begin{array}{l}5 \% \\
\text { Limits }\end{array}$ & $\begin{array}{l}\text { Wald } \\
\text { Chi- } \\
\text { Square }\end{array}$ & $\operatorname{Pr}>$ ChiSq \\
\hline Age & 0.0039 & 0.0032 & -0.0023 & 0.010 & 1.52 & 0.217 \\
\hline Gender & 0.219 & 0.073 & 0.075 & 0.362 & 8.92 & 0.0028 \\
\hline Ethnicity & 0.031 & 0.148 & -0.259 & 0.321 & 0.04 & 0.833 \\
\hline $\begin{array}{l}\text { Treatment } \\
\text { condition }\end{array}$ & 0.373 & 0.125 & 0.128 & 0.617 & 8.90 & 0.0029 \\
\hline Patient study & -0.205 & 0.074 & -0.350 & -0.060 & 7.70 & 0.0055 \\
\hline Worksite study & 0.070 & 0.098 & -0.122 & 0.262 & 0.51 & 0.476 \\
\hline Baseline SOC & 0.115 & 0.026 & 0.063 & 0.166 & 19.05 & $<.0001$ \\
\hline $\begin{array}{l}\text { Standardized } \\
\text { baseline severity }\end{array}$ & 0.361 & 0.037 & 0.290 & 0.433 & 98.14 & $<.0001$ \\
\hline $\begin{array}{l}\text { Baseline severity } \\
\mathrm{x} \text { treatment } \\
\text { condition }\end{array}$ & -0.025 & 0.049 & -0.120 & 0.070 & 0.26 & 0.609 \\
\hline
\end{tabular}


Table 22

Z-scores, smoking and sun protection, with standardized severity

\begin{tabular}{lccccc}
\hline & $\mathrm{B}$ & $\begin{array}{c}\text { Standard } \\
\text { Error }\end{array}$ & $\mathrm{t}$ Value & $\mathrm{p}$ & $\beta$ \\
\hline Age & 0.0043 & 0.0051 & 0.84 & 0.400 & 0.029 \\
Gender & 0.220 & 0.105 & 2.09 & 0.038 & 0.075 \\
Ethnicity & -0.513 & 0.250 & -2.05 & 0.041 & -0.070 \\
Treatment condition & 0.132 & 0.260 & 0.51 & 0.611 & 0.045 \\
Patient study & -0.012 & 0.114 & -0.11 & 0.915 & -0.0041 \\
Worksite study & 0.222 & 0.172 & 1.29 & 0.198 & 0.051 \\
Baseline SOC & 0.123 & 0.048 & 2.55 & 0.011 & 0.104 \\
Standardized baseline severity & 0.551 & 0.047 & 11.66 & $<.0001$ & 0.580 \\
Baseline severity x treatment & -0.016 & 0.066 & -0.24 & 0.810 & -0.022 \\
condition & & & & & \\
\hline
\end{tabular}


Table 23

Z-scores, diet and smoking, with standardized severity

\begin{tabular}{lccccc}
\hline & $\mathrm{B}$ & $\begin{array}{c}\text { Standard } \\
\text { Error }\end{array}$ & $\mathrm{t}$ Value & $\mathrm{p}$ & $\beta$ \\
\hline Age & -0.0014 & 0.0042 & -0.33 & 0.743 & -0.0097 \\
Gender & 0.240 & 0.092 & 2.62 & 0.0090 & 0.082 \\
Ethnicity & -0.434 & 0.204 & -2.12 & 0.034 & -0.062 \\
Treatment condition & 0.415 & 0.186 & 2.23 & 0.026 & 0.145 \\
Patient study & -0.054 & 0.093 & -0.58 & 0.562 & -0.019 \\
Worksite study & 0.135 & 0.142 & 0.96 & 0.340 & 0.032 \\
Baseline SOC & 0.039 & 0.035 & 1.10 & 0.273 & 0.033 \\
Standardized baseline severity & 0.515 & 0.035 & 14.71 & $<.0001$ & 0.568 \\
Baseline severity x treatment & 0.050 & 0.055 & 0.90 & 0.366 & 0.061 \\
condition & & & & & \\
\hline
\end{tabular}


Table 24

Z scores diet and sun, with standardized severity

\begin{tabular}{lccccc}
\hline & B & $\begin{array}{c}\text { Standard } \\
\text { Error }\end{array}$ & t Value & $p$ & $\beta$ \\
\hline Age & 0.0066 & 0.0021 & 3.20 & 0.0014 & 0.044 \\
Gender & 0.297 & 0.046 & 6.43 & $<.0001$ & 0.092 \\
Ethnicity & -0.137 & 0.099 & -1.38 & 0.166 & -0.019 \\
Treatment condition & 0.511 & 0.094 & 5.42 & $<.0001$ & 0.158 \\
Patient study & -0.176 & 0.051 & -3.43 & 0.0006 & -0.054 \\
Worksite study & 0.0083 & 0.068 & 0.12 & 0.903 & 0.0020 \\
Baseline SOC & 0.067 & 0.018 & 3.78 & 0.0002 & 0.055 \\
Standardized baseline severity & 0.640 & 0.019 & 33.08 & $<.0001$ & 0.626 \\
Baseline severity x treatment & 0.022 & 0.028 & 0.78 & 0.436 & 0.024 \\
condition & & & & & \\
\hline
\end{tabular}


Table 25

Standardized Residuals

\begin{tabular}{lccccccc}
\hline & $\mathrm{N}$ & Min & Max & Mean & SD & Skew & Kurtosis \\
\hline Smoking & 816 & -6.50 & 3.07 & 0.00 & 1.0 & -1.43 & 7.07 \\
DBQ & 4152 & -8.33 & 4.80 & 0.00 & 1.0 & -0.03 & 2.05 \\
SPBS & 2849 & -5.63 & 4.26 & 0.00 & 1.0 & 0.02 & 1.07 \\
\hline
\end{tabular}


Table 26

Standardized Residuals Smoking and Sun, with standardized severity

\begin{tabular}{lccccc}
\hline & B & $\begin{array}{c}\text { Standard } \\
\text { Error }\end{array}$ & t Value & $p$ & $\beta$ \\
\hline Age & 0.0038 & 0.0070 & 0.54 & 0.591 & 0.024 \\
Gender & 0.277 & 0.145 & 1.91 & 0.057 & 0.089 \\
Ethnicity & -0.607 & 0.344 & -1.77 & 0.078 & -0.079 \\
Treatment condition & 0.175 & 0.358 & 0.49 & 0.625 & 0.056 \\
Patient study & 0.029 & 0.156 & 0.19 & 0.852 & 0.0095 \\
Worksite study & 0.377 & 0.237 & 1.59 & 0.112 & 0.082 \\
Baseline SOC & 0.102 & 0.067 & 1.53 & 0.127 & 0.081 \\
Standardized baseline severity & 0.051 & 0.065 & 0.79 & 0.429 & 0.051 \\
Baseline severity x treatment condition & -0.024 & 0.091 & -0.27 & 0.790 & -0.032 \\
\hline
\end{tabular}


Table 27

Standardize Residuals, smoking and diet, with standardized severity

\begin{tabular}{lccccc}
\hline & B & $\begin{array}{c}\text { Standard } \\
\text { Error }\end{array}$ & t Value & $p$ & $\beta$ \\
\hline Age & -0.0062 & 0.0060 & -1.04 & 0.298 & -0.039 \\
Gender & 0.255 & 0.129 & 1.97 & 0.049 & 0.079 \\
Ethnicity & -0.452 & 0.288 & -1.57 & 0.117 & -0.059 \\
Treatment condition & 0.587 & 0.263 & 2.23 & 0.026 & 0.187 \\
Patient study & -0.046 & 0.131 & -0.35 & 0.725 & -0.015 \\
Worksite study & 0.267 & 0.200 & 1.34 & 0.182 & 0.057 \\
Baseline SOC & 0.039 & 0.050 & 0.79 & 0.428 & 0.031 \\
Standardized baseline severity & -0.040 & 0.049 & -0.81 & 0.418 & -0.040 \\
Baseline severity x treatment condition & 0.077 & 0.078 & 0.99 & 0.325 & 0.086 \\
\hline
\end{tabular}


Table 28

Standardized Residuals sun and diet, with standardized severity

\begin{tabular}{lccccc}
\hline & $\mathrm{B}$ & $\begin{array}{c}\text { Standard } \\
\text { Error }\end{array}$ & $\mathrm{t}$ Value & $\mathrm{p}$ & $\beta$ \\
\hline Age & 0.0085 & 0.0027 & 3.11 & 0.0019 & 0.058 \\
Gender & 0.387 & 0.061 & 6.37 & $<.0001$ & 0.125 \\
Ethnicity & -0.184 & 0.130 & -1.42 & 0.157 & -0.026 \\
Treatment condition & 0.673 & 0.124 & 5.42 & $<.0001$ & 0.217 \\
Patient study & -0.231 & 0.067 & -3.42 & 0.0006 & -0.075 \\
Worksite study & 0.0077 & 0.090 & 0.09 & 0.932 & 0.0019 \\
Baseline SOC & 0.093 & 0.023 & 3.97 & $<.0001$ & 0.080 \\
Standardized baseline severity & -0.017 & 0.025 & -0.66 & 0.507 & -0.017 \\
Baseline severity x treatment & 0.029 & 0.036 & 0.79 & 0.428 & 0.034 \\
condition & & & & & \\
\hline
\end{tabular}


Table 29

Discriminant Function Analysis, smoking and sun summative indices, overall effect

\begin{tabular}{lcccc}
\hline & Value & F Value & $\operatorname{Pr}>\mathrm{F}$ & $\eta^{2}$ \\
\hline Wilks' Lambda & 0.839 & 5.11 & $<.0001$ & .161 \\
Pillai's Trace & 0.164 & 4.99 & $<.0001$ & \\
Hotelling-Lawley Trace & 0.188 & 5.24 & $<.0001$ & \\
Roy's Greatest Root & 0.166 & 9.26 & $<.0001$ & \\
\hline
\end{tabular}


Table 30

Discriminant Function Analysis, smoking and sun summative indices, discriminant loadings

\begin{tabular}{lcc}
\hline & Can1 & Can2 \\
\hline Age & 0.029 & -0.370 \\
Gender & 0.0049 & -0.475 \\
Ethnicity & -0.194 & 0.537 \\
Treatment condition & 0.825 & 1.353 \\
Patient study & -0.1001 & 0.093 \\
Worksite study & -0.035 & 0.147 \\
Baseline SOC & 0.613 & -0.380 \\
Standardized baseline severity & 0.290 & 0.034 \\
Baseline severity x treatment & 0.529 & 1.474 \\
condition & & \\
\hline
\end{tabular}


Table 31

Discriminant Function Analysis, smoking and diet summative indices, overall effect

\begin{tabular}{lcccc}
\hline & Value & F Value & $\operatorname{Pr}>\mathrm{F}$ & $\eta^{2}$ \\
\hline Wilks' Lambda & 0.903 & 4.14 & $<.0001$ & .097 \\
Pillai's Trace & 0.098 & 4.08 & $<.0001$ & \\
Hotelling-Lawley Trace & 0.106 & 4.20 & $<.0001$ & \\
Roy's Greatest Root & 0.094 & 7.44 & $<.0001$ & \\
\hline
\end{tabular}


Table 32

Discriminant Function Analysis, smoking and diet summative indices, discriminant loadings

\begin{tabular}{lcc}
\hline & Can1 & Can2 \\
\hline Age & -0.059 & 0.181 \\
Gender & -0.156 & -0.193 \\
Ethnicity & -0.166 & 0.852 \\
Treatment condition & 0.485 & -0.244 \\
Patient study & -0.165 & 0.126 \\
Worksite study & 0.065 & -0.149 \\
Baseline SOC & 0.276 & 0.031 \\
Standardized baseline severity & 0.781 & 0.306 \\
Baseline severity x treatment condition & 0.206 & -0.604 \\
\hline
\end{tabular}


Table 33

Discriminant Function Analysis, sun and diet summative indices, overall effect

\begin{tabular}{lcccc}
\hline & Value & F Value & $\operatorname{Pr}>\mathrm{F}$ & $\eta^{2}$ \\
\hline Wilks' Lambda & 0.840 & 27.94 & $<.0001$ & .160 \\
Pillai's Trace & 0.160 & 26.84 & $<.0001$ & \\
Hotelling-Lawley Trace & 0.189 & 29.04 & $<.0001$ & \\
Roy's Greatest Root & 0.183 & 56.42 & $<.0001$ & \\
\hline
\end{tabular}


Table 34

Discriminant Function Analysis diet and sun summative indices, discriminant loadings

\begin{tabular}{lcc}
\hline & Can1 & Can2 \\
\hline Age & 0.060 & -0.048 \\
Gender & 0.182 & -0.177 \\
Ethnicity & 0.020 & 0.046 \\
Treatment condition & 0.680 & 1.866 \\
Patient study & -0.178 & 0.049 \\
Worksite study & 0.025 & -0.129 \\
Baseline SOC & 0.250 & 0.102 \\
Standardized baseline severity & 0.608 & -0.851 \\
Baseline severity x treatment condition & 0.376 & 1.475 \\
\hline
\end{tabular}


Table 35

Discriminant Function Analysis, smoking and sun, stage of change, overall effect

\begin{tabular}{lrrrr}
\hline & Value & F Value & $\operatorname{Pr}>\mathrm{F}$ & $\eta^{2}$ \\
\hline Wilks' Lambda & 0.629 & 3.33 & $<.0001$ & .371 \\
Pillai's Trace & 0.415 & 3.06 & $<.0001$ & \\
Hotelling-Lawley Trace & 0.525 & 3.61 & $<.0001$ & \\
Roy's Greatest Root & 0.380 & 21.22 & $<.0001$ & \\
\hline
\end{tabular}


Table 36

Discriminant Function Analysis, smoking and sun, stage of change, discriminant loadings

\begin{tabular}{|c|c|c|c|c|c|c|c|c|}
\hline & Can1 & Can2 & Can3 & Can4 & Can5 & Can6 & Can7 & Can8 \\
\hline Age & 0.119 & -0.117 & -0.409 & 0.041 & 0.157 & -0.294 & 0.141 & 0.753 \\
\hline Gender & -0.038 & 0.828 & -0.504 & -0.138 & -0.032 & 0.090 & 0.370 & -0.120 \\
\hline Ethnicity & -0.045 & -0.196 & 0.029 & 0.600 & 0.573 & 0.173 & 0.461 & -0.187 \\
\hline $\begin{array}{l}\text { Treatment } \\
\text { condition }\end{array}$ & 0.306 & 0.906 & 0.681 & 1.701 & -0.933 & 0.557 & -0.535 & 0.992 \\
\hline Patient study & -0.033 & -0.073 & 0.145 & -0.344 & -0.071 & 0.850 & 0.393 & 0.406 \\
\hline Worksite study & -0.020 & -0.176 & -0.081 & -0.060 & -0.767 & 0.303 & 0.786 & -0.017 \\
\hline Baseline SOC & 0.747 & -0.103 & -0.612 & 0.114 & -0.175 & 0.263 & -0.271 & -0.270 \\
\hline $\begin{array}{l}\text { Standardized } \\
\text { baseline severity }\end{array}$ & 0.368 & -0.178 & 0.677 & -0.680 & 0.438 & -0.418 & 0.551 & -0.057 \\
\hline $\begin{array}{l}\text { Baseline severity } \\
\mathrm{x} \text { treatment } \\
\text { condition }\end{array}$ & 0.059 & 0.830 & 0.640 & 1.701 & -0.826 & 1.067 & -0.799 & 0.729 \\
\hline
\end{tabular}


Table 37

Discriminant Function Analysis, smoking and diet, stage of change, overall effect

\begin{tabular}{lcccc}
\hline & Value & F Value & $\operatorname{Pr}>\mathrm{F}$ & $\eta^{2}$ \\
\hline Wilks' Lambda & 0.740 & 3.03 & $<.0001$ & .260 \\
Pillai's Trace & 0.279 & 2.87 & $<.0001$ & \\
Hotelling-Lawley Trace & 0.326 & 3.19 & $<.0001$ & \\
Roy's Greatest Root & 0.231 & 18.27 & $<.0001$ & \\
\hline
\end{tabular}


Table 38

Discriminant Function Analysis, smoking and diet, stage of change, discriminant loadings

\begin{tabular}{lcccccccc}
\hline & Can1 & Can2 & Can3 & Can4 & Can5 & Can6 & Can7 & Can8 \\
\hline Age & 0.0039 & 0.344 & 0.555 & -0.0071 & 0.072 & -0.636 & 0.370 & 0.229 \\
Gender & -0.032 & 0.276 & -0.131 & -0.091 & 0.695 & 0.016 & -0.338 & 0.292 \\
Ethnicity & -0.021 & 0.458 & 0.260 & 0.436 & 0.253 & 0.442 & 0.095 & -0.496 \\
Treatment & 0.240 & -0.697 & -0.743 & -0.049 & 0.712 & 0.246 & 1.742 & -0.267 \\
condition & & & & & & & & \\
Patient study & -0.024 & 0.231 & -0.204 & 0.020 & 0.171 & 0.538 & 0.160 & 0.804 \\
Worksite study & 0.041 & -0.351 & -0.154 & 0.560 & 0.602 & -0.090 & -0.173 & 0.489 \\
$\begin{array}{l}\text { Baseline SOC } \\
\text { Standardized }\end{array}$ & 0.821 & 0.297 & -0.403 & 0.083 & -0.093 & -0.303 & -0.033 & -0.118 \\
baseline & 0.423 & -0.306 & 0.935 & -0.069 & -0.282 & 0.324 & -0.489 & 0.210 \\
severity & & & & & & & & \\
Baseline & 0.076 & -0.553 & -0.873 & -0.659 & 1.041 & 0.059 & 1.547 & -0.674 \\
$\begin{array}{l}\text { severity x } \\
\text { treatment }\end{array}$ & & & & & & & & \\
condition & & & & & & & & \\
\hline
\end{tabular}


Table 39

Discriminant Function Analysis, sun and diet, stage of change, overall effect

\begin{tabular}{lcccc}
\hline & Value & F Value & $\operatorname{Pr}>\mathrm{F}$ & $\eta^{2}$ \\
\hline Wilks' Lambda & 0.697 & 14.29 & $<.0001$ & .303 \\
Pillai's Trace & 0.316 & 12.68 & $<.0001$ & \\
Hotelling-Lawley Trace & 0.416 & 15.96 & $<.0001$ & \\
Roy's Greatest Root & 0.367 & 113.04 & $<.0001$ & \\
\hline
\end{tabular}


Table 40

Discriminant Function Analysis, sun and diet, stage of change, discriminant loadings

\begin{tabular}{|c|c|c|c|c|c|c|c|c|}
\hline & Can1 & Can2 & Can3 & Can4 & Can5 & Can6 & Can7 & Can8 \\
\hline Age & 0.047 & 0.077 & 0.439 & 0.0061 & -0.185 & -0.179 & 0.801 & -0.318 \\
\hline Gender & 0.080 & 0.209 & 0.716 & -0.394 & -0.328 & 0.078 & -0.382 & -0.105 \\
\hline Ethnicity & 0.089 & -0.118 & 0.132 & -0.176 & 0.180 & 0.037 & 0.301 & 0.882 \\
\hline $\begin{array}{l}\text { Treatment } \\
\text { condition }\end{array}$ & 0.425 & 1.358 & -0.0082 & -0.457 & 1.174 & -1.035 & -0.110 & -0.171 \\
\hline Patient study & -0.097 & -0.154 & 0.487 & 0.296 & 0.824 & 0.593 & -0.087 & -0.122 \\
\hline $\begin{array}{l}\text { Worksite } \\
\text { study }\end{array}$ & 0.00016 & 0.248 & 0.827 & 0.556 & 0.097 & 0.277 & -0.203 & 0.172 \\
\hline $\begin{array}{l}\text { Baseline } \\
\text { SOC }\end{array}$ & 0.550 & -0.620 & 0.156 & -0.295 & 0.116 & -0.267 & -0.117 & -0.151 \\
\hline $\begin{array}{l}\text { Standardized } \\
\text { baseline } \\
\text { severity }\end{array}$ & 0.571 & -0.019 & -0.374 & 0.534 & -0.431 & 0.804 & 0.179 & 0.198 \\
\hline $\begin{array}{l}\text { Baseline } \\
\text { severity } \mathrm{x} \\
\text { treatment } \\
\text { condition }\end{array}$ & 0.183 & 0.964 & 0.086 & 0.103 & 1.236 & -1.645 & -0.359 & -0.101 \\
\hline
\end{tabular}


Table 41

Descriptives of Composite Post-Intervention Stage of Change

\begin{tabular}{lccccccc}
\hline & $\mathrm{N}$ & Min & Max & Mean & SD & Skew & Kurtosis \\
\hline $\begin{array}{l}\text { DBQ \& } \\
\text { Smoking }\end{array}$ & 766 & 2.00 & 10.00 & 4.40 & 1.94 & .612 & -.345 \\
DBQ \& SUN & 2794 & 2.00 & 10.00 & 4.68 & 2.17 & .544 & -.465 \\
$\begin{array}{l}\text { Smoking \& } \\
\text { SUN }\end{array}$ & 544 & 2.00 & 10.00 & 4.43 & 1.89 & .559 & -.339 \\
& & & & & & & \\
\hline
\end{tabular}


Table 42

Post-intervention Composite Stage of Change

\begin{tabular}{|c|c|c|c|}
\hline Behavior Pair & Total Stage of Change Score & Frequency & Percentage \\
\hline \multirow[t]{9}{*}{ Smoking \& Sun } & 2 & 97 & $17.8 \%$ \\
\hline & 3 & 107 & $19.7 \%$ \\
\hline & 4 & 93 & $17.1 \%$ \\
\hline & 5 & 101 & $18.6 \%$ \\
\hline & 6 & 51 & $9.4 \%$ \\
\hline & 7 & 67 & $12.3 \%$ \\
\hline & 8 & 13 & $2.4 \%$ \\
\hline & 9 & 10 & $1.8 \%$ \\
\hline & 10 & 5 & $.9 \%$ \\
\hline \multirow[t]{9}{*}{ Smoking \& Diet } & 2 & 146 & $19.1 \%$ \\
\hline & 3 & 157 & $20.5 \%$ \\
\hline & 4 & 125 & $16.3 \%$ \\
\hline & 5 & 130 & $17.0 \%$ \\
\hline & 6 & 78 & $10.2 \%$ \\
\hline & 7 & 77 & $10.1 \%$ \\
\hline & 8 & 31 & $4.0 \%$ \\
\hline & 9 & 14 & $1.8 \%$ \\
\hline & 10 & 8 & $1.0 \%$ \\
\hline
\end{tabular}




\begin{tabular}{llll}
\hline Behavior Pair & Total Stage of Change Score & Frequency & Percentage \\
\hline Sun \& Diet & 2 & 607 & $21.7 \%$ \\
& 3 & 304 & $10.9 \%$ \\
& 4 & 591 & $21.2 \%$ \\
5 & 285 & $10.2 \%$ \\
6 & 474 & $17.0 \%$ \\
& 7 & 173 & $6.2 \%$ \\
& 8 & 233 & $8.3 \%$ \\
& 10 & 30 & $1.1 \%$ \\
& & 97 & $3.5 \%$ \\
\hline
\end{tabular}


Table 43

Post-Intervention, sun and smoking, without standardized severity

\begin{tabular}{lccccc}
\hline & $\mathrm{B}$ & $\begin{array}{c}\text { Standard } \\
\text { Error }\end{array}$ & $\mathrm{t}$ Value & $\mathrm{p}$ & $\beta$ \\
\hline Age & 0.0088 & 0.0074 & 1.19 & 0.235 & 0.045 \\
Gender & 0.153 & 0.150 & 1.02 & 0.308 & 0.039 \\
Ethnicity & -0.471 & 0.340 & -1.39 & 0.167 & -0.052 \\
Treatment condition & 0.503 & 0.147 & 3.42 & 0.0007 & 0.130 \\
Patient study & -0.074 & 0.166 & -0.44 & 0.657 & -0.019 \\
Worksite study & -0.120 & 0.247 & -0.49 & 0.627 & -0.021 \\
Baseline SOC & 0.740 & 0.059 & 12.45 & $<.0001$ & 0.472 \\
\hline
\end{tabular}


Table 44

Post-Intervention, diet and smoking, without standardized severity

\begin{tabular}{lccccc}
\hline & $\mathrm{B}$ & $\begin{array}{c}\text { Standard } \\
\text { Error }\end{array}$ & $\mathrm{t}$ Value & $\mathrm{p}$ & $\beta$ \\
\hline Age & 0.0026 & 0.0069 & 0.38 & 0.701 & 0.013 \\
Gender & 0.142 & 0.144 & 0.98 & 0.327 & 0.034 \\
Ethnicity & -0.301 & 0.327 & -0.92 & 0.358 & -0.032 \\
Treatment condition & 0.342 & 0.137 & 2.49 & 0.013 & 0.086 \\
Patient study & -0.161 & 0.154 & -1.04 & 0.298 & -0.041 \\
Worksite study & 0.122 & 0.230 & 0.53 & 0.595 & 0.021 \\
Baseline SOC & 0.543 & 0.057 & 9.58 & $<.0001$ & 0.332 \\
\hline
\end{tabular}


Table 45

Post-Intervention Stage of Change, sun and diet, without standardized severity

\begin{tabular}{lccccc}
\hline & B & $\begin{array}{c}\text { Standard } \\
\text { Error }\end{array}$ & t Value & $p$ & $\beta$ \\
\hline Age & 0.010 & 0.0036 & 2.81 & 0.0049 & 0.049 \\
Gender & 0.506 & 0.079 & 6.42 & $<.0001$ & 0.115 \\
Ethnicity & 0.086 & 0.171 & 0.50 & 0.615 & 0.0087 \\
Treatment condition & 0.662 & 0.076 & 8.76 & $<.0001$ & 0.151 \\
Patient study & -0.237 & 0.089 & -2.65 & 0.0080 & -0.054 \\
Worksite study & 0.046 & 0.119 & 0.39 & 0.697 & 0.0081 \\
Baseline SOC & 0.595 & 0.029 & 20.84 & $<.0001$ & 0.362 \\
\hline
\end{tabular}


Table 46

Post-Intervention Stage of Change, smoking and sun, with standardized severity

\begin{tabular}{lccccc}
\hline & $\mathrm{B}$ & $\begin{array}{c}\text { Standard } \\
\text { Error }\end{array}$ & $\mathrm{t}$ Value & $\mathrm{p}$ & $\beta$ \\
\hline Age & 0.0083 & 0.0075 & 1.10 & 0.271 & 0.043 \\
Gender & -0.056 & 0.156 & -0.36 & 0.718 & -0.015 \\
Ethnicity & -0.216 & 0.348 & -0.62 & 0.536 & -0.024 \\
Treatment condition & 0.627 & 0.384 & 1.63 & 0.103 & 0.162 \\
Patient study & -0.034 & 0.169 & -0.20 & 0.842 & -0.0087 \\
Worksite study & -0.078 & 0.258 & -0.30 & 0.763 & -0.013 \\
Baseline SOC & 0.569 & 0.072 & 7.94 & $<.0001$ & 0.365 \\
Standardized baseline severity & 0.233 & 0.069 & 3.36 & 0.0008 & 0.188 \\
Baseline severity x treatment & 0.050 & 0.097 & 0.51 & 0.610 & 0.052 \\
condition & & & & & \\
\hline
\end{tabular}


Table 47

Post-Intervention Stage of Change, smoking and diet, with standardized severity

\begin{tabular}{lccccc}
\hline & $\mathrm{B}$ & $\begin{array}{c}\text { Standard } \\
\text { Error }\end{array}$ & $\mathrm{t}$ Value & $\mathrm{p}$ & $\beta$ \\
\hline Age & 0.00063 & 0.0069 & 0.09 & 0.927 & 0.0032 \\
Gender & -0.133 & 0.152 & -0.88 & 0.380 & -0.032 \\
Ethnicity & -0.196 & 0.330 & -0.59 & 0.554 & -0.020 \\
Treatment condition & 0.380 & 0.308 & 1.23 & 0.218 & 0.095 \\
Patient study & -0.113 & 0.155 & -0.73 & 0.464 & -0.029 \\
Worksite study & 0.181 & 0.238 & 0.76 & 0.447 & 0.030 \\
Baseline SOC & 0.452 & 0.058 & 7.74 & $<.0001$ & 0.276 \\
Standardized baseline severity & 0.277 & 0.058 & 4.78 & $<.0001$ & 0.218 \\
Baseline severity x treatment & 0.024 & 0.091 & 0.27 & 0.790 & 0.021 \\
condition & & & & & \\
\hline
\end{tabular}


Table 48

Post-Intervention Stage of Change, sun and diet, with standardized severity

\begin{tabular}{lccccc}
\hline & $\mathrm{B}$ & $\begin{array}{c}\text { Standard } \\
\text { Error }\end{array}$ & $\mathrm{t}$ Value & $\mathrm{p}$ & $\beta$ \\
\hline Age & 0.0052 & 0.0035 & 1.51 & 0.131 & 0.025 \\
Gender & 0.215 & 0.077 & 2.79 & 0.0054 & 0.049 \\
Ethnicity & 0.358 & 0.164 & 2.17 & 0.030 & 0.036 \\
Treatment condition & 0.983 & 0.157 & 6.25 & $<.0001$ & 0.224 \\
Patient study & -0.199 & 0.085 & -2.34 & 0.020 & -0.045 \\
Worksite study & 0.054 & 0.113 & 0.47 & 0.636 & 0.0094 \\
Baseline SOC & 0.404 & 0.030 & 13.65 & $<.0001$ & 0.246 \\
Standardized baseline severity & 0.372 & 0.032 & 11.55 & $<.0001$ & 0.269 \\
Baseline severity x treatment & 0.124 & 0.046 & 2.69 & 0.0072 & 0.102 \\
condition & & & & & \\
\hline
\end{tabular}


Table 49

Summary of effect sizes

\begin{tabular}{llll}
\hline Pairs & $\begin{array}{l}\text { Sun \& } \\
\text { Smoke }\end{array}$ & $\begin{array}{l}\text { Smoke \& } \\
\text { Diet }\end{array}$ & $\begin{array}{l}\text { Diet \& } \\
\text { Sun }\end{array}$ \\
\hline Summative Index MR $\left(\mathrm{R}^{2}\right)$ & .124 & .035 & .089 \\
Summative Index Poisson & - & - & - \\
Summative Index $\left(\mathrm{R}^{2}\right)$ with standardized & .141 & .084 & .154 \\
severity & & & \\
Summative Index Poisson with std severity & - & - & - \\
Z-Score $\left(\mathrm{R}^{2}\right)$ with std severity & .436 & .411 & .506 \\
Std Residual (R $\left.{ }^{2}\right)$ with std severity & .035 & .028 & .064 \\
DFA (sum index) (1-wilks lambda) & .161 & .100 & .160 \\
DFA (TTM) (1-wilks lambda) & .371 & .260 & .303 \\
TTM score (just SOC) (R $\left.\mathrm{R}^{2}\right)$ & .244 & .120 & .182 \\
TTM score with std severity $\left(\mathrm{R}^{2}\right)$ & .270 & .159 & .257 \\
\hline
\end{tabular}




\section{BIBLIOGRAPHY}

Anderson, G. \& Horvath, J. (2004). The growing burden of chronic disease in America. Public Health Reports, 119, 263-270.

Baer, H. J., Glynn, R. J., Hu, F. B., Hankinson, S. E., Willett, W. C., Colditz, G. A., Stampfer, M., \& Rosner, B. (2010). Risk factors for mortality in the Nurses' Health Study: a competing risks analysis. American Journal of Epidemiology, 173, 319-329.

Berrigan, D., Dodd, K., Troiano, R. P., Krebs-Smith, S. M., \& Barbash, R. B. (2003).Patterns of health behavior in U. S. adults. Preventive Medicine, 36, 615-623.

Blair, S. N., Horton, E., Leon, A. S., Lee, I., Drinkwater, B. L., Dishman, R. K., Mackey, M., \& Kienholz, M. L. (1996).Physical activity, nutrition and chronic disease. Medicine \& Science in Sports \& Exercise, 28, 335-349.

Blissmer, B., Prochaska, J. O., Velicer, W. F., Redding, C. A., Rossi, J. S., Greene, G. W., Paiva, A., \& Robbins, M. (2010). Common factors predicting long-term changes in multiple health behaviors. Journal of Health Psychology, 15, 205214.

Buller, D. B., Cokkinides, V., Hall, H. I., Hartman, A. M., Saraiya,, M., Miller, E., Paddock, L., \& Glanz, K. (2011). Prevalence of sunburn, sun protection, and indoor tanning behaviors among Americans: review from national surveys and case studies of 3 states. Journal of the American Academy of Dermatology, 65, S114.e1-S114.e11. 
Carlson, J. A., Sallis, J. F., Ramirez, E. R., Patrick, K., \& Norman, G. J. (2012). Physical activity and dietary behavior change in internet-based weight loss interventions: comparing two multiple-behavior change indices. Preventive Medicine, 54, 50-54.

Center for Disease Control and Prevention (2007).Fruit and vegetable consumption among adults -United States, 2005. Morbidity and Mortality Weekly Report, 56(10), 213-217.

Center for Disease Control and Prevention (2012).Current cigarette smoking among adults-United States, 2011.Morbidity and Mortality Weekly Report, 61(44), 889-894.

Center for Disease Control and Prevention (2013). Skin Cancer: Sun-Protective Behavior Rates. Accessed November 11, 2015 from http://www.cdc.gov/cancer/skin/statistics/behavior.htm

Cohen, J. (1992). A power primer. Psychological Bulletin, 112, 155-159.

Cohen, J., Cohen, P., West, S. G., \& Aiken, L. S. (2003). Applied Multiple Regression/ Correlation Analysis for the Behavioral Sciences, $3^{\text {rd }}$ edition. Mahwah, NJ: Lawrence Erlbaum Associates, Publishers.

Coups, E. J. \& Ostroff, J. S. A population-based estimate of the prevalence of behavioral risk factors among adult cancer survivors and noncancer controls. Preventive Medicine, 40, 702-711. 
Dehghan, M., Akhtar-Danesh, N., \& Merchant, A. T. (2011) Factors associated with fruit and vegetable consumption among adults. Journal of Human Nutrition and Dietetics, 24, 128-134.

Demark-Wahnefried, W., Aziz, N. M., Rowland, J. H., \& Pinto, B. M. (2005). Riding the crest of the teachable moment: promoting long-term health after the diagnosis of cancer. Journal of Clinical Oncology, 23(24), 5814-5830.

DiClemente, C. C., Prochaska, J. O., Fairhurst, S., Velicer, W. F., Rossi, J. S., \& Velasquez, M. (1991). The process of smoking cessation: an analysis of precontemplation, contemplation, and contemplation/action. Journal of Consulting \& Clinical Psychology, 59, 295-304.

Drake, B. F., Quintilani, L. M., Sapp, A. L., Li, Y., Harley, A. E., Emmons, K., M., \& Sorensen, G. (2013). Comparing strategies to assess multiple behavior change in behavioral research. Translational Behavioral Medicine, 3, 114-121.

Fagerstrom, K. O., Heatherton, T. F., \& Kozlowski, L. T. (1990). Nicotine addiction and its assessment. Ear, Nose, Throat Journal, 69, 763-765.

Ford, E. S., Bergmann, M. M., Boeing, H., Li, C., \& Capewell, S. (2012). Healthy lifestyle behaviors and all-cause mortality among adults in the United States. Preventive Medicine, 55, 23-27.

Ginns, P. \& Barrie, S. (2004). Reliability of single item ratings of quality in higher education: a replication. Psychological Reports, 95, 1023-1030. 
Graham, J. W. (2012). Missing Data: Analysis and Design. New York, NY: Springer Science + Business Media.

Greene, G. W., Redding, C. A., Prochaska, J. O., Paiva, A. L., Rossi, J. S., Velicer, W. F., Blissmer, B., \& Robbins, M. L. (2013). Baseline transtheoretical and dietary behavioral predictors of dietary fat moderation over 12 and 24 months. Eating Behaviors, 14, 255-262.

Greene, G.W., Rossi, S.R., Fava, J.L., Velicer, W.F., Laforge, R.G., Willey, C., \& Rossi, J.S. (1996). The relationship between dietary intake and a behavior questionnaire. Annals of Behavioral Medicine, 18 (supplement), S188.

Greene, G., Rossi, S., Reed, G., Willey, C., \&Prochaska, J. (1994). Stages of change for reducing dietary fat to $30 \%$ of energy or less. Journal of American Dietetic Association, 94, 1105-1110.

Hall, K. L. \& Rossi, J. S. (2008).Meta-analytic examination of the strong and weak principles across 48 health behaviors. Preventive Medicine, 48, 266-274.

Hammond, D., Fong, G. T., McNeil, A., Borland, R., \& Cummings, K. M. (2006). Effectiveness of cigarette warning labels in informing smokers about the risks of smoking: findings from the International Tobacco Control (ITC) Four Country Survey. Tobacco Control, 15(supp 3), iii19-iii25.

Harlow, L. L. (2014). The Essence of Multivariate Thinking (2 ${ }^{\text {nd }}$ ed.). New York, NY: Routledge. 
Jamal, A., Agaku, I. T., O’Connor, E., King, B. A., Kenemer, J. B., \& Neff, L. (2014). Current cigarette smoking among adults—-United States, 2005-2013. Morbidity and Mortality Weekly Report, 63(47), 1108-1112.

Jarvis, M. J., Cohen, J. E., Delnevo, C. D., \& Giovino, G. A. (2013). Dispelling myths about gender differences in smoking cessation: population data from the US, Canada and Britain. Tobacco Control, 22(5), 358-362.

Kirkpatrick, S. I., Dodd, K. W., Reedy, J., \& Krebs-Smith, S. M. (2011). Income and race/ethnicity are associated with adherence to food-based dietary guidelines among US adults and children. Journal of the Academy of Nutrition and Dietetics, 112, 624-635.

Kobayashi, H. (2012). Multiple behavior analytic techniques. (Doctoral dissertation). Retrieved from UMI Dissertation Publishing (3546510).

Kobayashi, H., Rossi, J.S., Redding, C.A., \&Prochaska, J.O. (2014). Comparison of alternative composite multiple behavior outcomes measures for high-risk adults. Annals of Behavioral Medicine, 47, S100.

Loef, M. \&Walach, H. (2012). The combined effects of healthy lifestyle behaviors on all cause mortality: a systematic review and meta-analysis. Preventive Medicine, 55, 163-170.

Loprinzi, P. D. \& Cardinal, B. J. (2012). Interrelationships among physical activity, depression, homocysteine, and metabolic syndrome with special considerations by sex. Preventive Medicine, 54(6), 388-392. 
Mathers, C. D. \& Loncar, D. (2006). Projections of global mortality and burden of disease from 2002 to 2030. PLOS Medicine, 3, 2011-2030.

National Cancer Institute (2008).Cancer Trends Progress Report-2009/2010 Update: Sun Protection. Bethesda, MD: National Institutes of Health, U.S. Department of Health and Human Services.

National Research Council (1989). Diet and Health: Implications for Reducing Chronic Disease. Washington DC: National Academy Press.

Noar, S. M., Chabot, M., \& Zimmerman, R. S. (2008). Applying health behavior theory to multiple behavior change: considerations and approaches. Preventive Medicine, 46, 275-280.

Noar, S. M. \& Zimmerman, R. S. (2005). Health behavior theory and cumulative knowledge regarding health behaviors: are we moving in the right direction? Health Education Research, 20, 275-290.

Osbourne J. \& Waters, E. (2002). Four assumptions of multiple regression that researchers should always test. Practical Assessment, Research \& Evaluation, 8(2), Accessed September 28, 2015 from http://PAREonline.net/getvn.asp? $\mathrm{v}=8 \& n=2$.

Painter, J. E., Borba, C. P., Hynes, M., Mays, D., \&Glanz, K. (2008). The use of theory in health behavior research from 2000 to 2005: a systematic review. Annuals of Behavioral Medicine, 35, 358-362. 
Paiva, A. L., Prochaska, J. O., Yin, H., Rossi, J. S., Redding, C. A., Blissmer, B., Robbins, M. L., Velicer, W. F., Lipschitz, J., Amoyal, N., Babbin, S. F., Blaney, C. L., Sillice, M. A., Fernandez, A., McGee, H. \& Horiuchi, S. (2012). Treated individuals who progress to action or maintenance for one behavior are more likely to make similar progress on another behavior: coaction results of a pooled data analysis of three trials. Preventive Medicine, 54, 331-334.

Parry, C., Kent, E. E., Mariotto, A. B., Alfanso, C. M., \& Rowland, J. H. (2011). Cancer survivors: a booming population. Cancer Epidemiological Biomarkers \& Prevention, 20, 1996-2005.

Pinto, B. M. \& Trunzo, J. J. (2005). Health behavior during and after a cancer diagnosis. Cancer, 104(S11), 2614-2623.

Prochaska, J. J., Spring, B., \& Nigg, C. R. (2008a). Multiple health behavior change research: an introduction and overview. Preventive Medicine, 46, 181-188.

Prochaska, J. J., Velicer, W. F., Nigg, C. R., \& Prochaska, J. O. (2008b). Methods of quantifying change in multiple risk factor interventions. Preventive Medicine, $46,260-265$.

Prochaska, J. O. (1994). Strong and weak principles for progressing from precontemplation to action on the basis of twelve problem behaviors. Health Psychology, 13, 47-51.

Prochaska, J. O. (2008). Multiple health behavior research represents the future of preventive medicine. Preventive Medicine, 46, 281-285. 
Prochaska, J. O., \& DiClemente, C. C. (1984).The Transtheoretical Model Approach: Crossing Traditional Boundaries of Change. Homewood, IL: Dow Jones/Irwin.

Prochaska, J. O., Velicer, W. F., DiClemente, C. C., \& Fava, J. L. (1988). Measuring processes of change: applications to the cessation of smoking. Journal of Consulting \& Clinical Psychology, 56, 520-528.

Prochaska, J. O., Velicer, W. F., Redding, C., Rossi, J. S., Goldstein, M., DePue, J., Greene, G. W., Rossi, S. R., Sun, X., Fava, J. L., Laforge, R., Rakowski, W., Plummer, B. A. (2005). Stage-based expert systems to guide a population of primary care patients to quit smoking, eat healthier, prevent skin cancer, and receive regular mammograms. Preventive Medicine, 41, 406-416.

Prochaska, J. O., Velicer, W. F., Rossi, J. S., Goldstein, M. G., Marcus, B. H., Rakowski, W., Fiore, C., Harlow, L. L., Redding, C. A., Rossenbloom, D., \& Rossi, S. R. (1994). Stages of change and decisional balance for 12 problem behaviors. Health Psychology, 13, 39-46.

Prochaska, J. O., Velicer, W. F., Rossi, J. S., Redding, C. A., Greene, G. W., Rossi, S. R., Sun, X., Fava, J. L., Laforge, R., \& Plummer, B. A. (2004). Multiple risk expert interventions: impact of simultaneous stage-matched expert system interventions for smoking, high-fat diet, and sun exposure in a population of parents. Health Psychology, 23, 503-516.

Redding, C.A., Prochaska, J.O., Paiva, A., Rossi, J.S., Velicer, W.F., Blissmer, B., Greene, G.W., Robbins, M., Sun, X. (2011). Baseline stage, severity and effort 
effects differentiate stable smokers from maintainers and relapsers. Substance Use \& Misuse, 46, 1664-1674.

Rossi, J.S. (2013). Statistical power analysis. In J.A. Schinka \& W.F. Velicer (Eds.), Handbook of psychology. Volume 2: Research methods in psychology $\left(2^{\text {nd }}\right.$ ed., pp. 71-108). (I.B. Weiner, Editor-in-Chief). John Wiley \& Sons.

Rossi, S. R., Ding, L., Rossi, J. S., Velicer, W. F., Greene, G. W., Fava, J. L., Laforge, R., Willey, C., \& Levesque, D. (1996). Development of a measure for dietary fat intake in large-scale survey research. Annals of Behavioral Medicine, 18, S237.

Schwab, U., Lauritzen, L., Tholstrup, T., Haldorsson, T. I., Riserus, U., Uusitupa, M., \& Becker, W. (2014). Effect of the amount and type of dietary fat on cardiometabolic risk factors and risk of developing type 2 diabetes, cardiovascular diseases, and cancer: a systematic review. Food \& Nutrition Research, 58, 1-26.

Trinidad, D. R., Pérez-Stable, E. J., White, M. M., Emery, S. L., \& Messer, K. (2011). A nationwide analysis of US racial/ethnic disparities in smoking behaviors, smoking cessation, and cessation-related factors. American Journal of Public Health, 101, 699-706.

Tucker, L. R., Damarin, F., \& Messick, S. (1966). A base-free measure of change. Psychometrika, 31(4), 457-473. 
U.S. Department of Agriculture \& U. S. Department of Health and Human Services (2010). Dietary Guidelines for Americans, 2010, $7^{\text {th }}$ Edition. Washington DC: U. S. Government Printing Office.

U.S. Department of Health and Human Services (1991).Healthy People 2000: National Health Promotion and Disease Prevention Objectives. DHHS Publication No. (PHS) 91-50212. Washington DC: U.S. Government Printing Office.

Underwood, J. M., Townsend, J. S., Stewart, S. L., Buchannan, N., Hawkins, N. A., Li, J., Peaker, B., Pollack, L. A., Richards, T. B., Rim, S. H., Rohan, E. A., Sabatino, S. A., Smith, J. L., Tai, E., Townsend, G., White, A., \& Fairley, T. (2012). Surveillance of demographic characteristics and health behaviors among adult cancer survivors-Behavioral Risk Factor Surveillance System, United States, 2009.Morbidity and Mortality Weekly Report, 61(1), 1-23.

Veldman, D. J. \& Brophy, J. E. (1974). Measuring teacher effects on pupil achievement. Journal of Educational Psychology, 66(3), 319-324.

Velicer, W. F., DiClemente, C.C., Rossi, J. S., \& Prochaska, J. O. (1990). Relapse situations and self-efficacy: an integrative model. Addictive Behaviors, 15, 271-283.

Velicer, W. F. \& Prochaska, J. O. (1999). An expert system intervention for smoking cessation. Patient Education \& Counseling, 36, 119-129. 
Velicer, W. F., Prochaska, J. O., Redding, C. A., Rossi, J. S., Sun, X., Rossi, S. R. \& Greene, G. W. (2004). Efficacy of expert system interventions for employees to decrease smoking, dietary fat, and sun exposure. International Journal of Behavioral Medicine, 11(S1), 277.

Velicer, W. F., Redding, C. A., Sun, X., \&Prochaska, J. O. (2007).Demographic variables, smoking variables, and outcome across five studies. Health Psychology, 26, 278-287.

Wanous, J. P. \& Hudy, M. J. (2001). Single item reliability: a replication and extension. Organizational Research Methods, 4(4), 361-375.

Weinstock, M. A., Rossi, J. S., Redding, C. A., \&Maddock, J. E. (2002). Randomized controlled community trial of the efficacy of a multicomponent stage-matched intervention to increase sun protection among beachgoers. Preventive Medicine, 35, 584-592.

Weinstock, M. A., Rossi, J. S., Redding, C. A., Maddock, J. E., \&Cottrill, S. D. (2000). Sun protection behaviors and stages of change for the primary prevention of skin cancers among beachgoers in southeastern New England. Annals of Behavioral Medicine, 22, 286-293.

Yin, H., Prochaska, J. O., Rossi, J. S., Redding, C. A., Paiva, A. L., Blissmer, B., Velicer, W. F., Johnson, S. S., \& Kobayashi, H. (2013). Treatment-enhanced paired action contributes substantially to change across multiple health behaviors: secondary analyses of five randomized trials. Translational Behavioral Medicine, 3, 62-71. 
Yusofov, M., Prochaska, J., Lipschitz, J., Gokbayrak, S., Paiva, A., Rossi, J., Redding, C., Velicer, W. (2014). Transtheoretical Principles and Processes for Sun Protection: A 24-Month Comparison of Successful Changers, Relapsers, and Non-changers. Annals of Behavioral Medicine, 47, S83.

Zheng, J., Hu, X., Zhao, Y., Yang, J., \& Li, D. (2013). Intake of fish and marine n-3 polyunsaturated fatty acids and risk of breast cancer: meta-analysis of data from 21 independent prospective cohort studies. British Medical Journal, $346,1-10$. 